تحليل مضمون الأفلام التليفزيونية القصيرة الإششادية الزراعية (التنويهات)

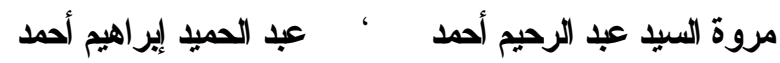

معهز بحوث الإرشاد الزراعي وللتتية الريفية- مركز البحوث الزرراعية- الجيزة- مصر

المستخلص

يهرف هذا البحث إلى تحديد مدى الالتز ام في إنتاج الأفلام التليفزيونية القصـيرة

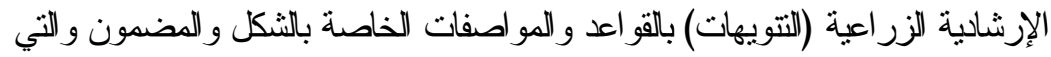

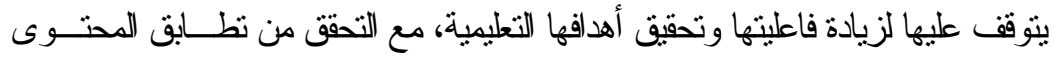

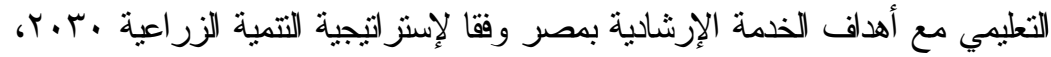

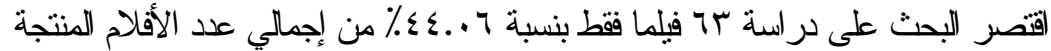

البالغ عددها بـ (فيلما وقت إجراء البحث، ونم تحليلها من حيث المحتوى و الثنكل، بإتباع

$$
\text { منهج تحليل المحتوى. وكاتت أهم النتائج على النحو الثلاي: }
$$

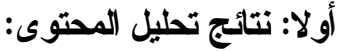

1- أوضحت النتائج أن مجالات الأهدلف الإرشادية للرئيسية و الفرعية المستمدة من إستراتيجية النتمية الزراعيــة

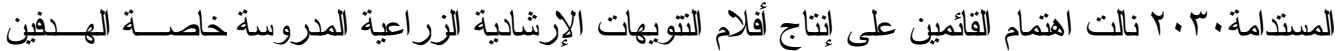

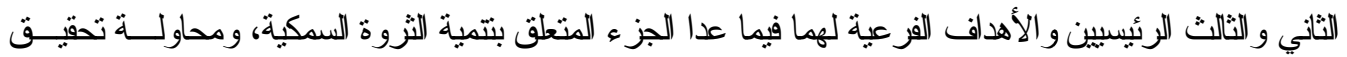

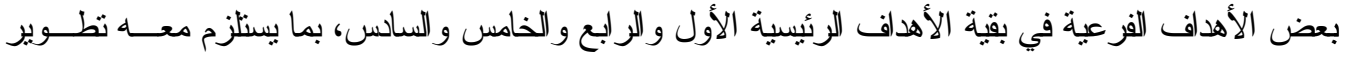

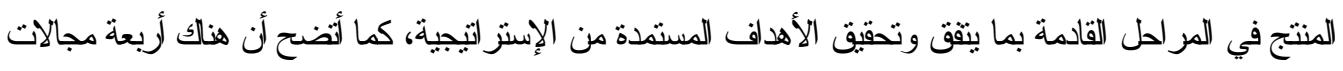

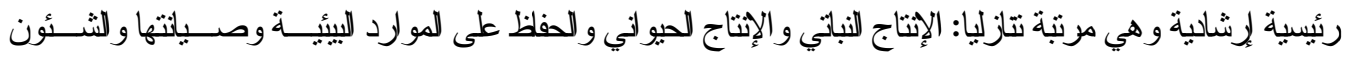

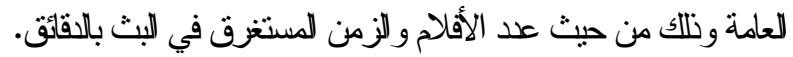

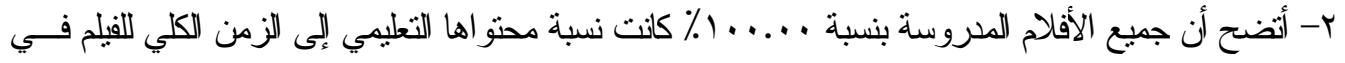

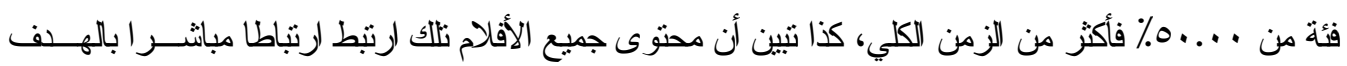

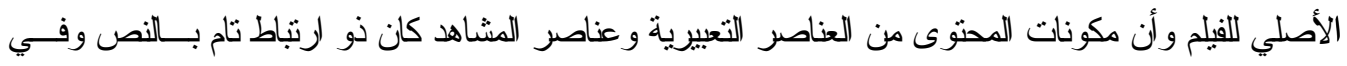
خدمة المحتوى حيث حملت أفكار و ومعانيه.

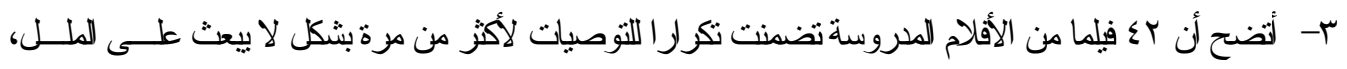

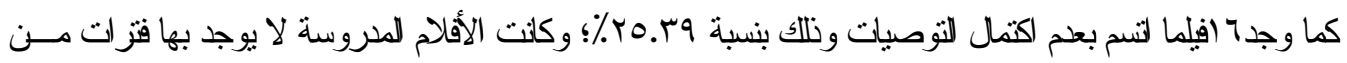
الصمت تسمح للمستهفين أن بتفاعو ا مع مشهد أو معلومة معينة.

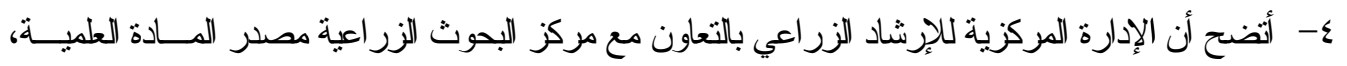

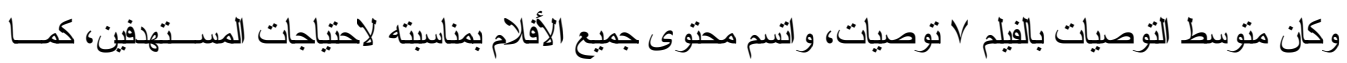
أنضح عدم وجود ملخص في نهاية كل فيلم من الأفلام المدروسة. 


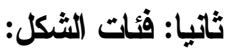

1- أوضحت النتائج استخدام المونتاج والأمثال الشعبية، وتعدد أماكن التصوير بالأفلام و انسامها بالو اقعية فجايت

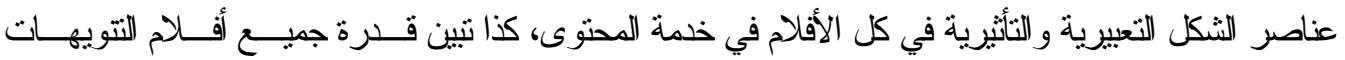

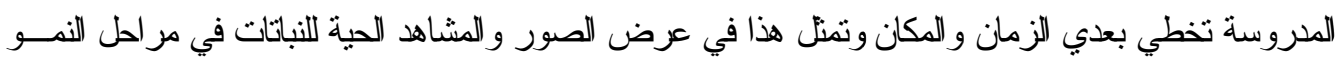
المختلفة طبقا للنوصية ونطبيق للنوصية بنفس الطريقة المطلوبة في للنوقيت الزمني الخاص بها.

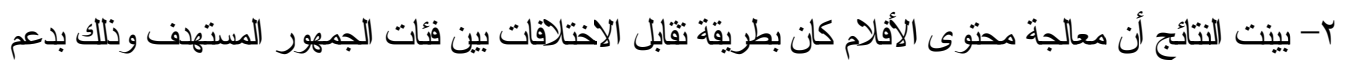

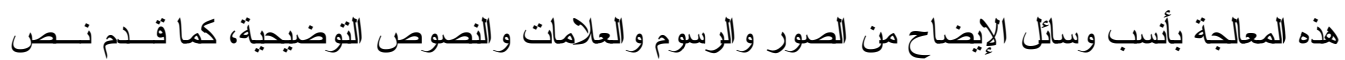
التعليق دعما في تزامنه مع الصورة.

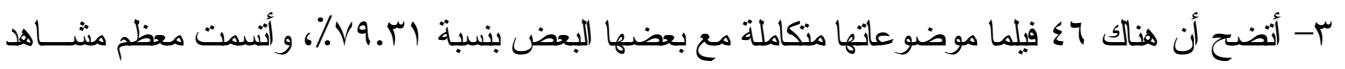

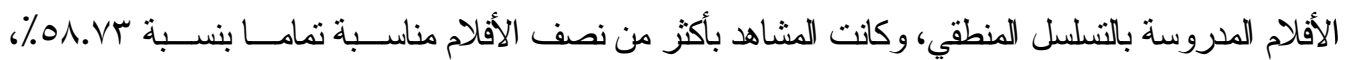

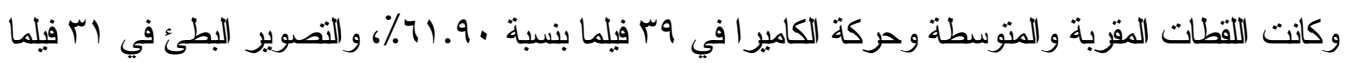

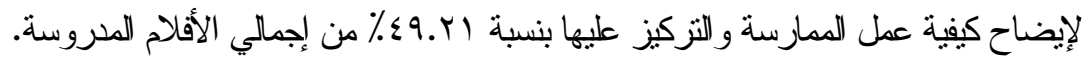

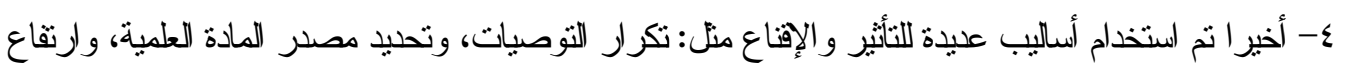

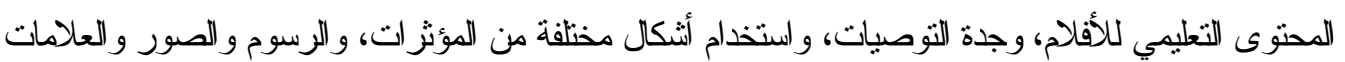

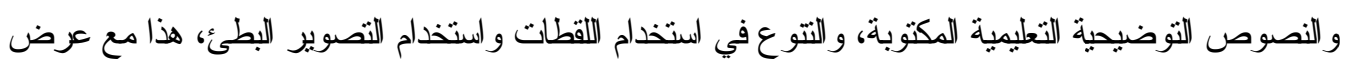
الجو انب الإيجابية من تطبيق التوصية، مع التوصية بالتوجه للمختص في حالة الحالات الحرجة.

\section{مقمة البحث}

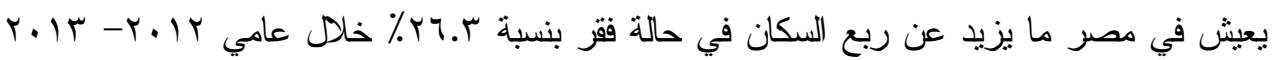

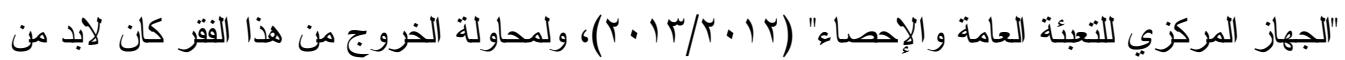
تطبيق السياسات التتموية الزراعية الريفية المستدامة في مصر لضمان نوعية حياة جيدة وكريمة لكافة المو اطنين و لا يتحقق ذلك بدون الحفاظ على النو ازن المقبول بين المكونات الثلاثة إنتاج غذاء كاف وآمن، لعدد مناسب من السكان، وحماية البيئة "MOALR; UNFPA; and FAO (4) (2005)، وتعنبر الخدمات الإرشادية الزر اعية التي تقدم بواسطة الجهاز الإرشادي الزر اعي جزء هاما من النتمية الزراعية الريفية،

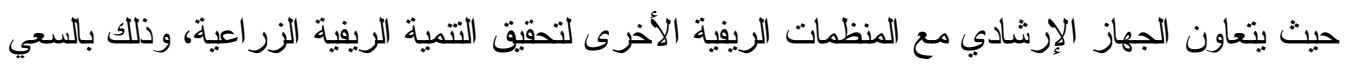

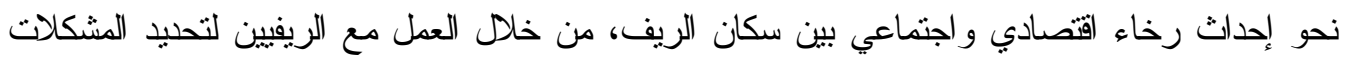
التي تو اجهم و أولوياتها، وتزويدهم بالمعارف و المهار ات التي تمكنهم من العمل على حل نلاء المشكلات

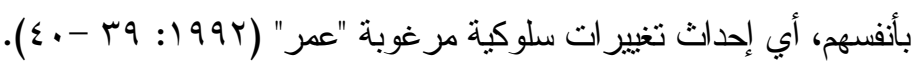

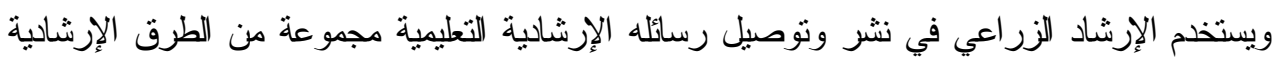

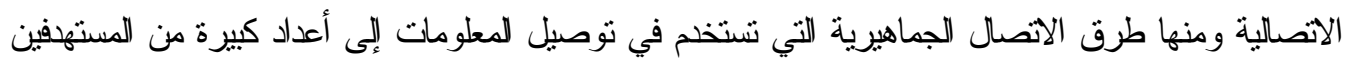

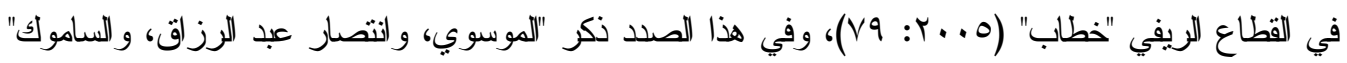

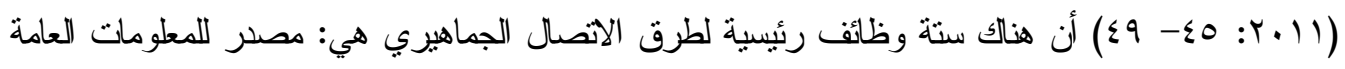
و المتخصصة في مجال معين للوقوف على أحثث الأخبار، ومحاولة تكوين رأي عام حول قضية ما، ونقل التزاث من جيل إلى أخر، وإمتاع وتزفيه المستهفين، ثم أضيفت وظيفتي الإفناع والحوار، ومع تطور الحاجات 
الاجتماعية و السياسية والاقصادية للمجتمعات للمختلفة ظهرت وظائف جديدة تتمنل في الوظائف التتموية و التعليمية و للنتقيفية و الإعلانية وخلق الدو الفع وتكوين الآر اءو الاتجاهات.

ومن ضمن أهم طرق الاتصال الجماهيرية السمعية البصرية القوبة التليفزيون لاكتسابه ميزة الصدق و الألفة

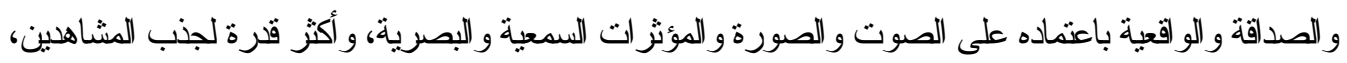

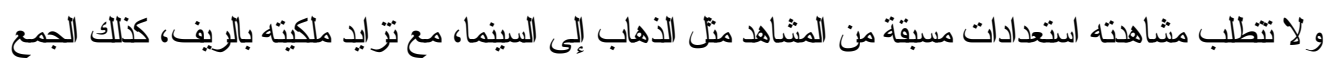

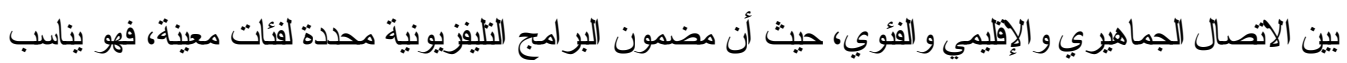

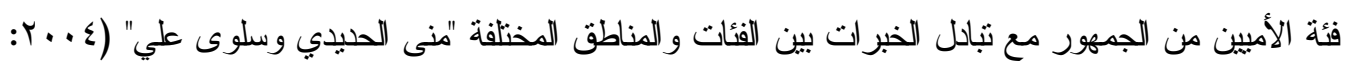

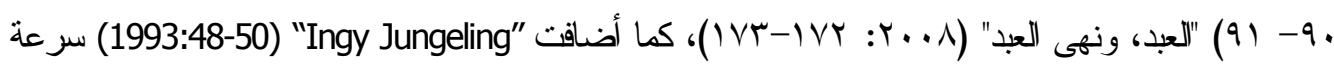
وصول البرامج الثليفزيونية إلى أعداد كييرة من المسترشدين بانتظام في نفس الوقت، كما أنه الأنسب في المراحل

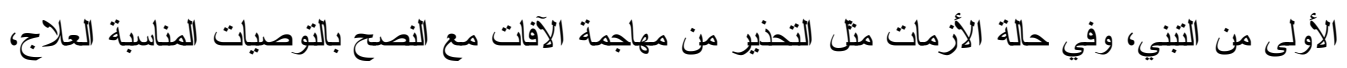

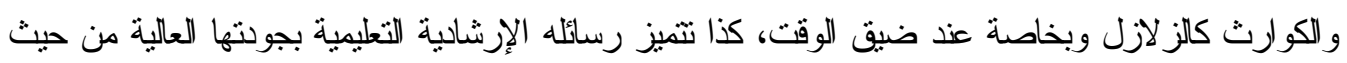

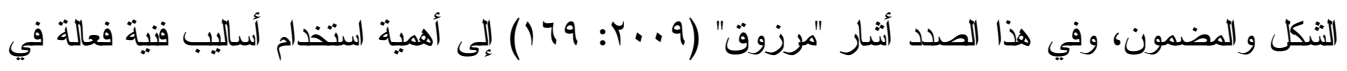

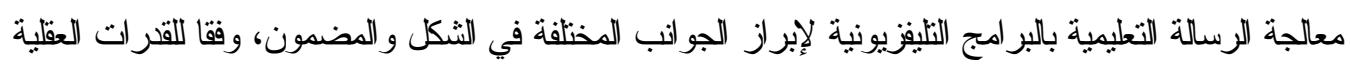

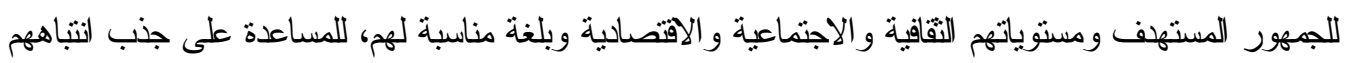

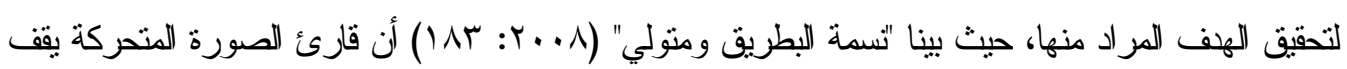

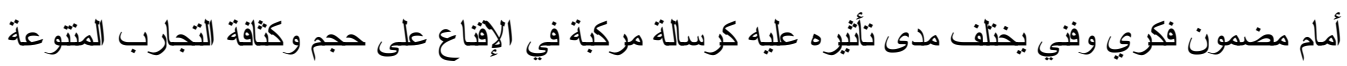
التي تحتويها هذه الصورة.

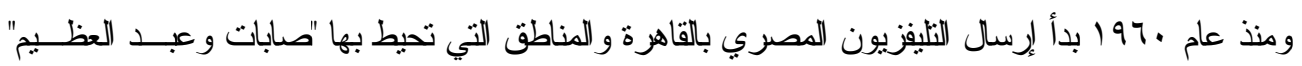

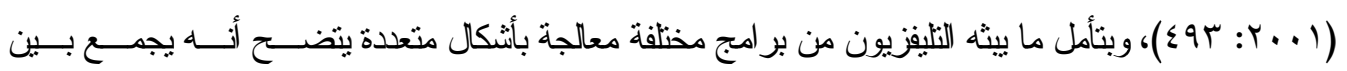

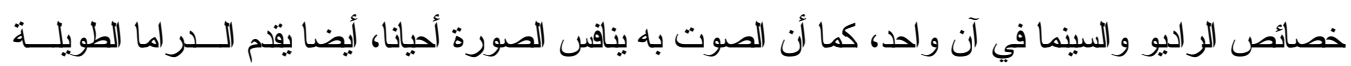

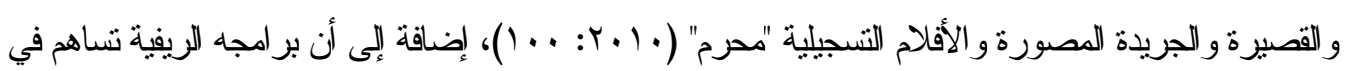

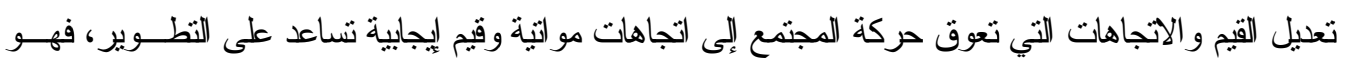

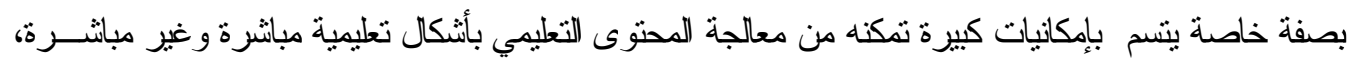

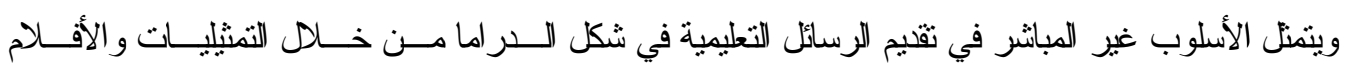

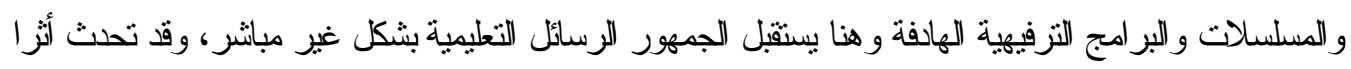

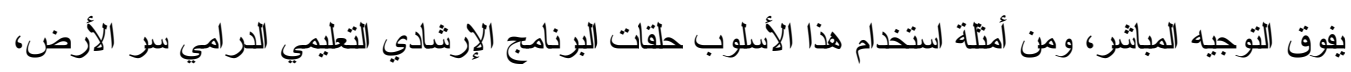

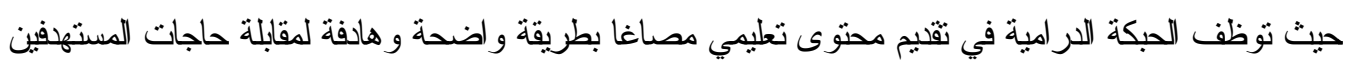

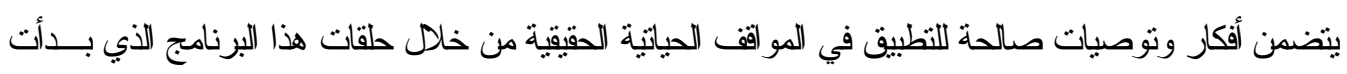

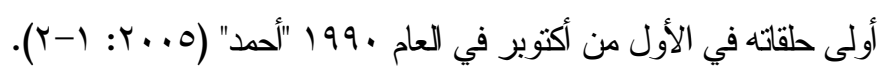

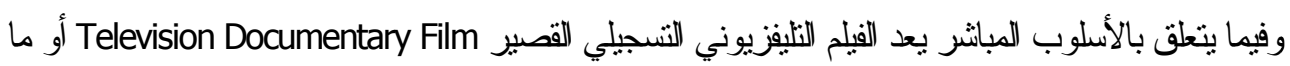

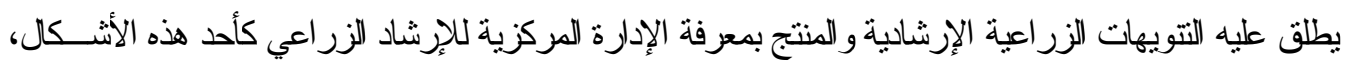

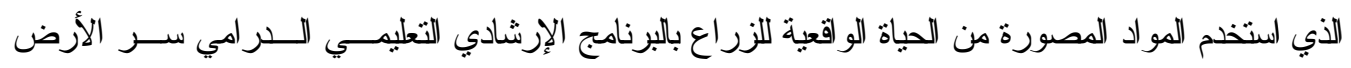

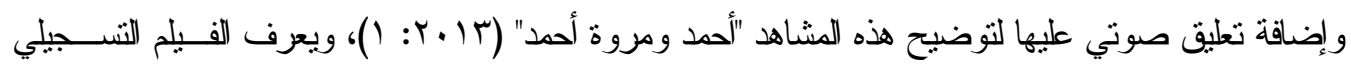




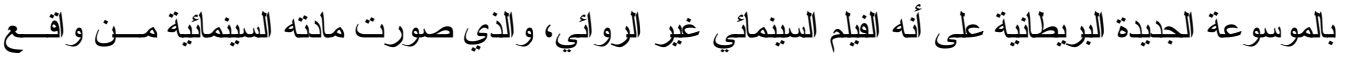

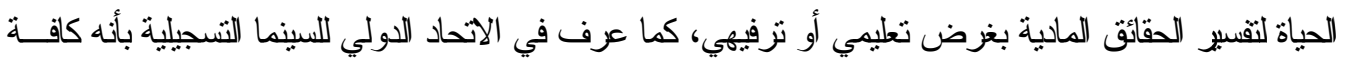

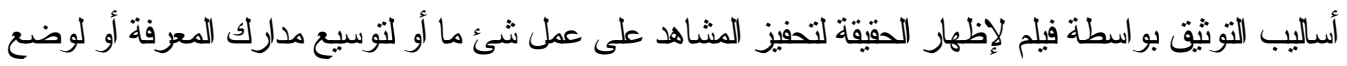
حول و اقعية لمختلف المشاكل بالمجالات الاقتصادية و العلاقات الإنسانية، كذا أكدت معظم تعريفات الفيلم التنجيلي

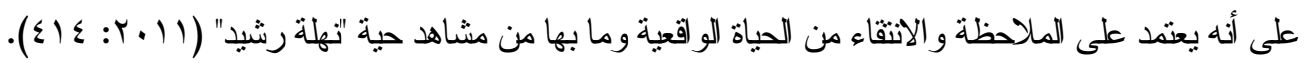

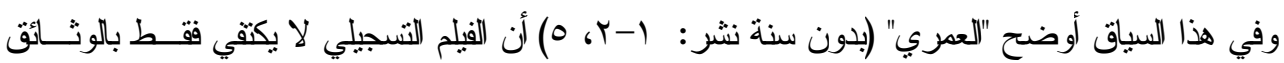

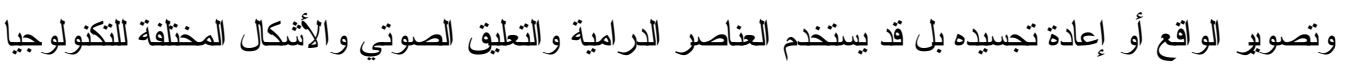

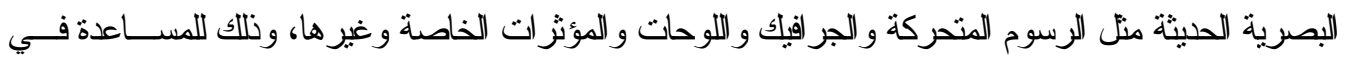

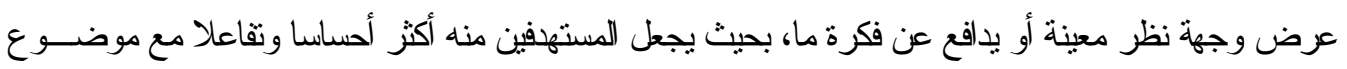
الفيلم، كما أنه يعكس مشكلات ووقائع الحاضر، كما يرى البعض أن الفيلم النتجيلي لا بستطيع أن بيتبأ بالمستقبل

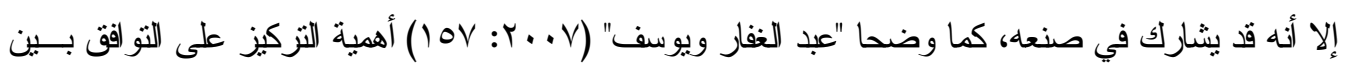

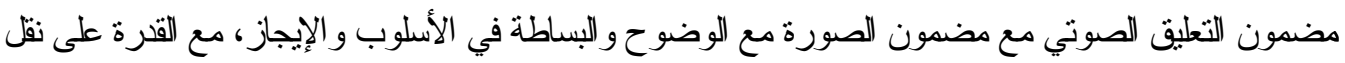
المعاني المطلوبة.

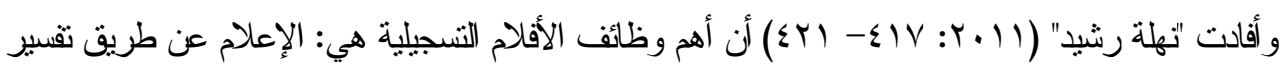

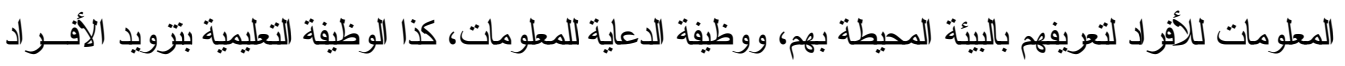

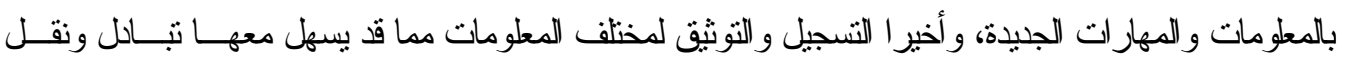

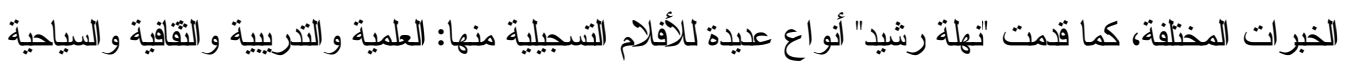

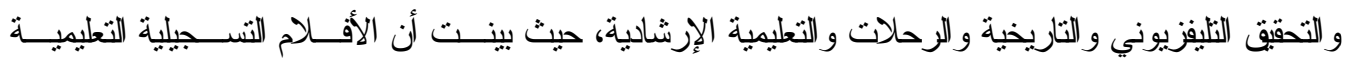

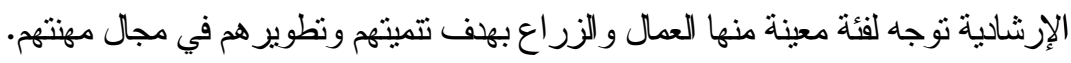

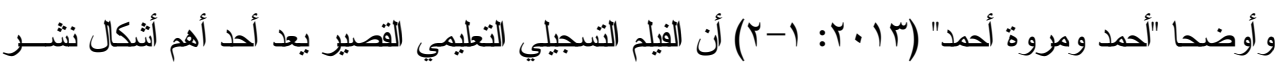

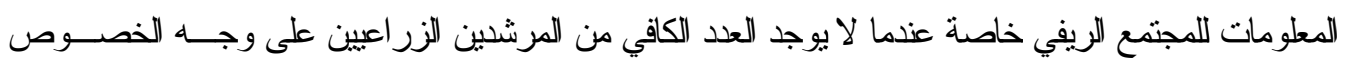

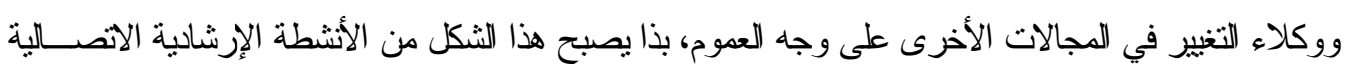

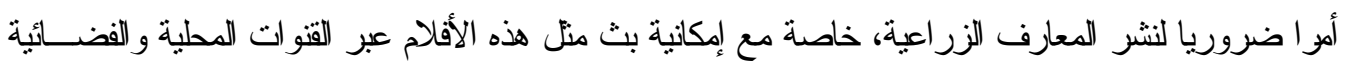

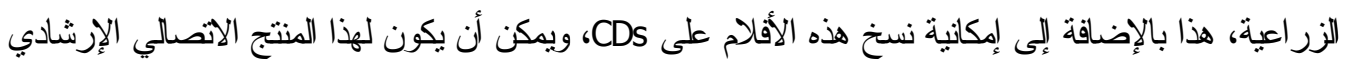

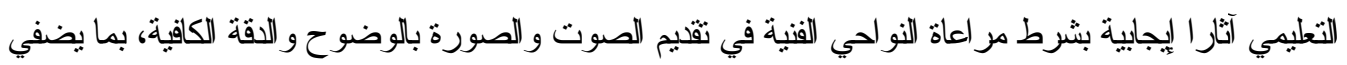
الإحساس بلاو اقعية على الصورة المعروضة خاصة إذا كان التعليق المتز امن مناسب ومعالج بشكل تعليمي يوضح

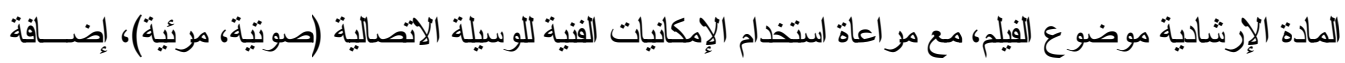
إلى توظيف الإضاءة وكافة المؤثرات الفنية لدعم الموقق التعليمي.

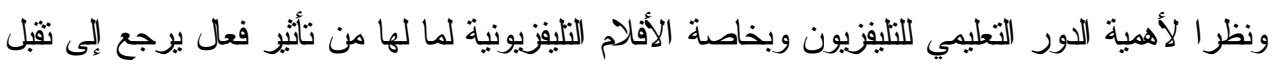

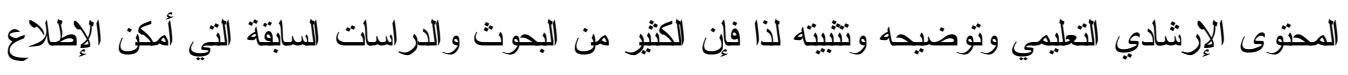

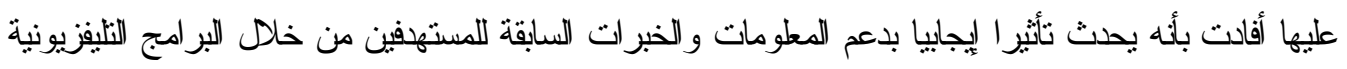

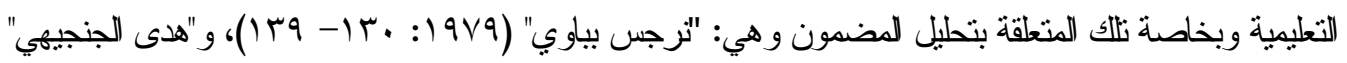

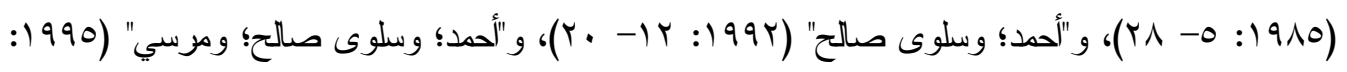

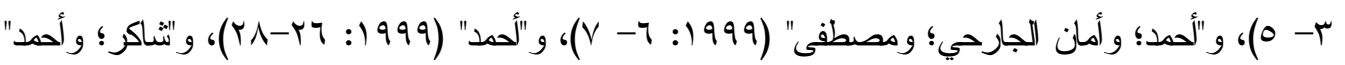




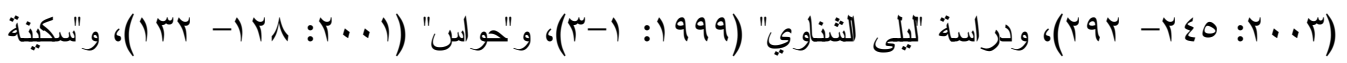

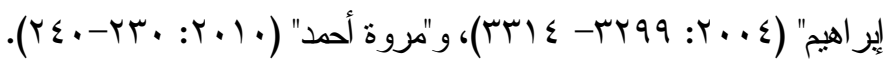
كما أوضحت دراسة "Silvia Balit" (15-16 : 1999) بالمؤتمر العالمي الر ابع للمر أة عن أهمية وسائل الإعلام

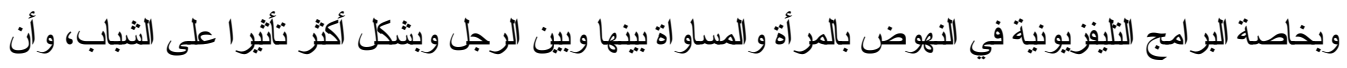

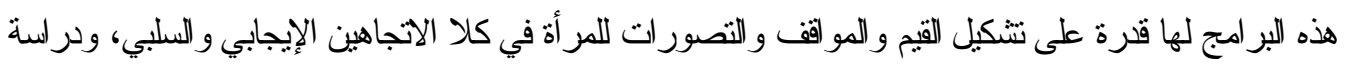

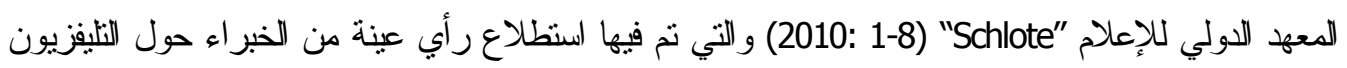

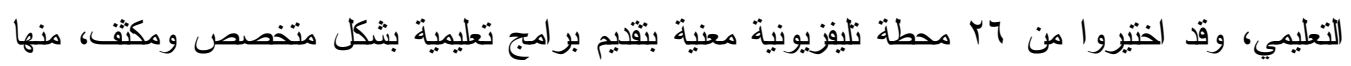

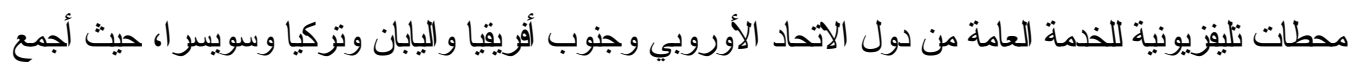

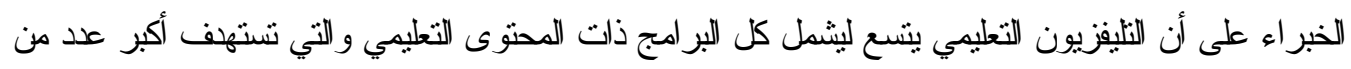
لجمهور باختلاف فئاتهم، ونقام مختلف الموضوعات (تعليم سياسي وتاريخي وجغر في وبيئي و الحياة الطبيعية،

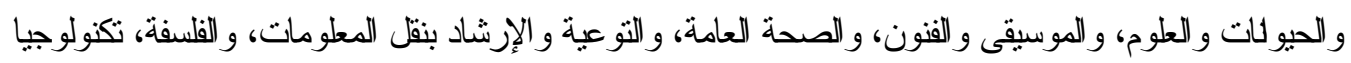

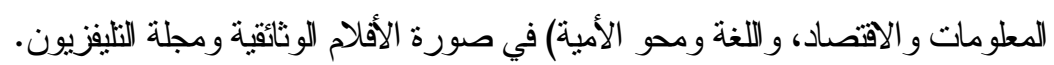

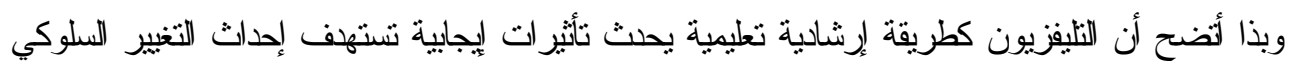
المطلوبهو تلك باستخدام قو الب فنية بمعلجة تعليمية تهاف إلى نقل المعلومات و المهار ات المختلفة للمستهوفين

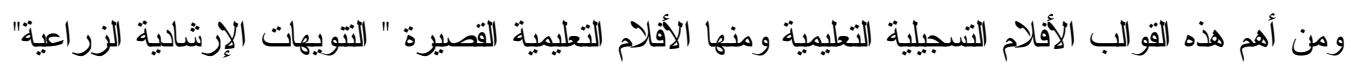
محل الدر اسة و التي ندر نتاولها بالبحث و الدر اسة.

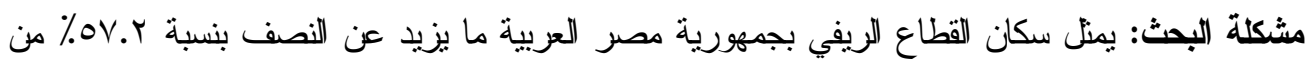

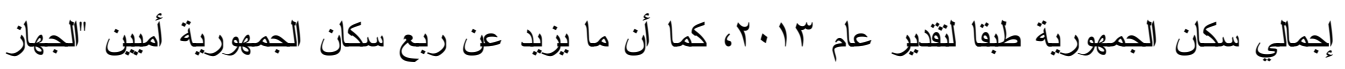

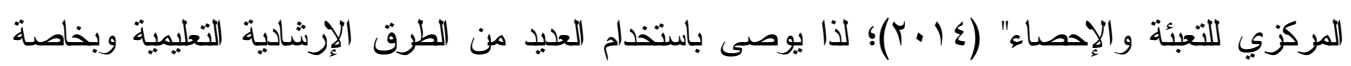

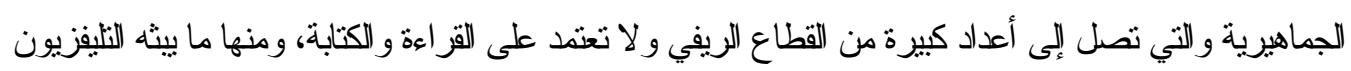

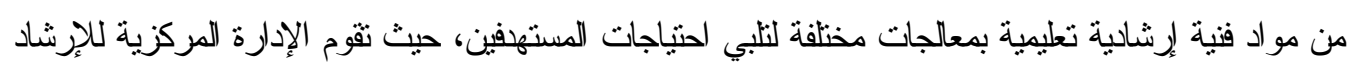
الزر اعي بإنتاج الأفلام التليفزيونية القصبيرة المسماة بالنتويهات لنقليم محتوى إرشادي تعليمي في فترة زئية زمنية

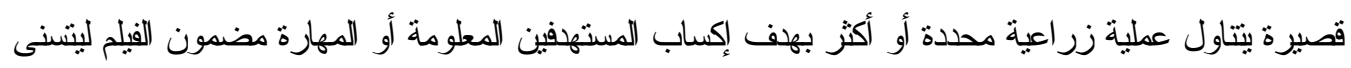

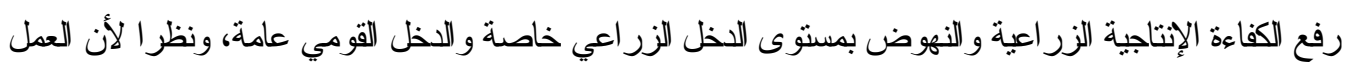

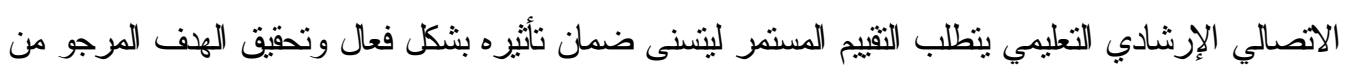

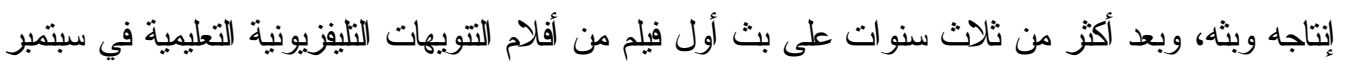

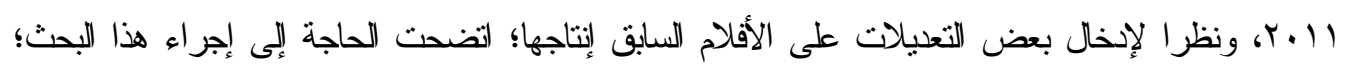

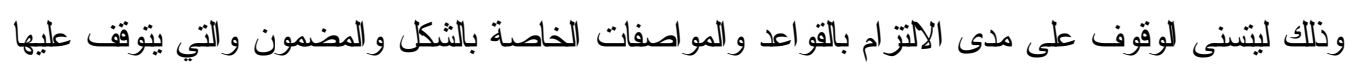
زيادة فاعلية هذه الأفلام وتحقيق أهدافها التعليمية مع التحقق من نطابق المحتوى التعليمي مع أهداف الخدمة الإزشادية.

أهداف البحث: انطلافا من العرض السابق لمشكلة البحث أمكن صياغة الأهداف التالية:

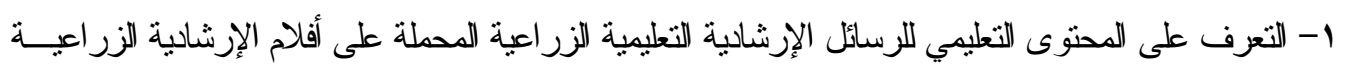

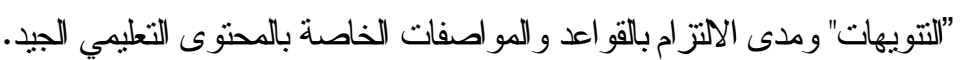


ץ- تحليد مكونات شكل القلب الاتصالي للرسائل الإرشادية التعليمية الزر اعية المحملة علــى أفــلام الإرشــادية الززر اعية "النتويهات" محل الدراسة.

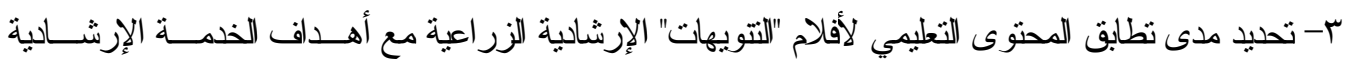

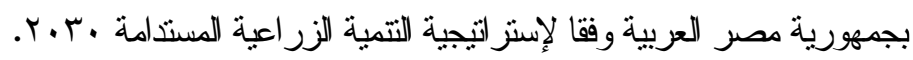
الطريقة البحثية

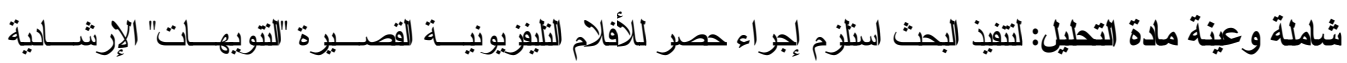

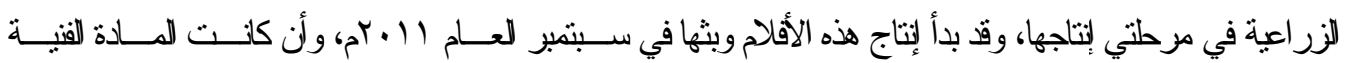

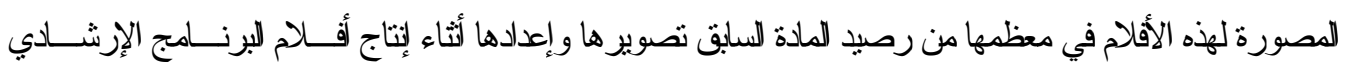

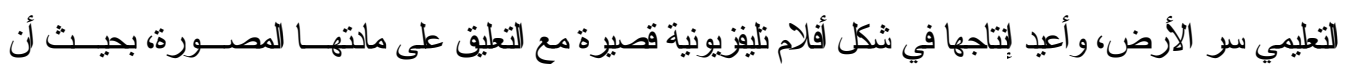

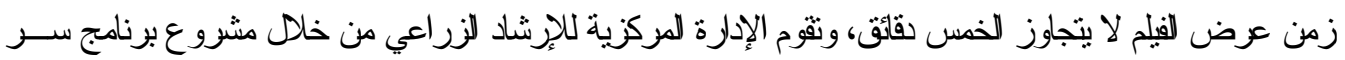

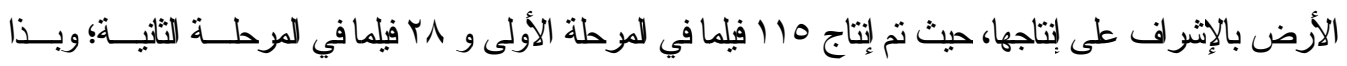

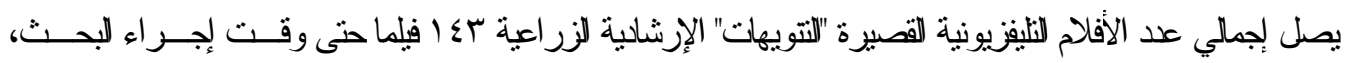

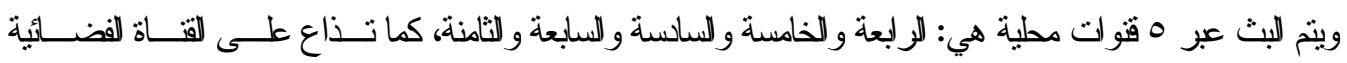

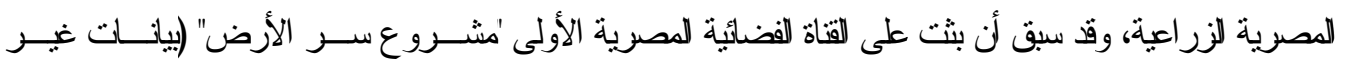

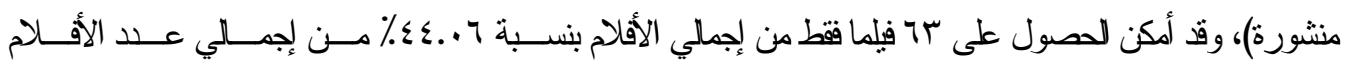
اللنتجة، حيث تم تحليلها من حيث الثنكل و المحتوى. المنهج البحثي المستخم: يعد هذا البحث من البحوث الوصفية وباستخدام تحليل المضمون كأداة لتحقيق أهـداف

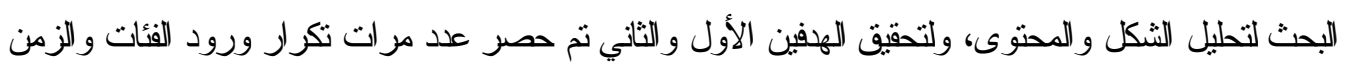

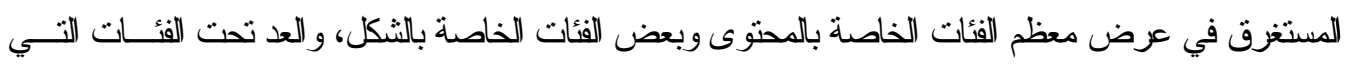

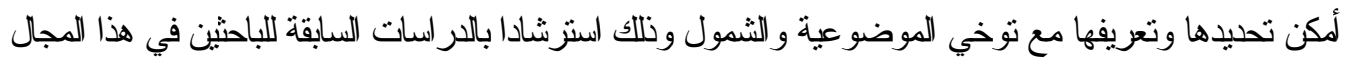
على النحو التالي: أ. فئات المحتوى (علدها س ا فئة): وقد أمكن تحديد وتعريف كل فئة على لانحو التالي:

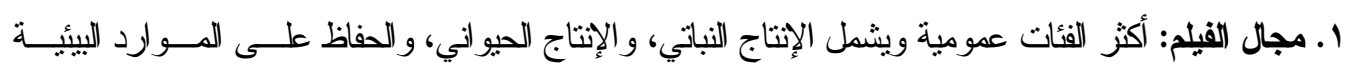
وصيانتها، و الثنئون العامة. r ـ المسلحة الزمنية للمحتوى التعليمي بالقيلم: يقصد بهز زمن المحتوى التعليمي بالفيلم مقاسا بالـــقائق مقارنـــة

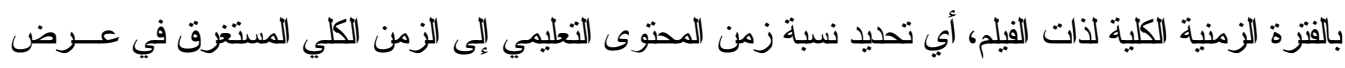
r. ارتباط المحتوى بهـف الفيلم : ويشمل ما يلي: الارنباط للمبانشر للمحتوى بالهرف الأصلي للفيلم: ويقصد بــهـ

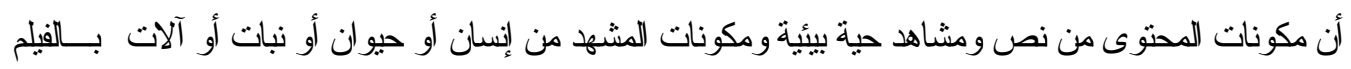

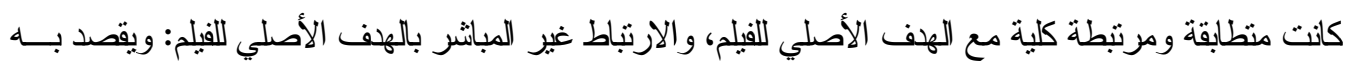

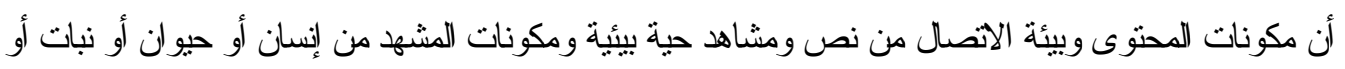
آلات بالفيلم تخدم وتمهد لتحقيق الهف الأصلي للفيلم ونلك من خلاد مسبيات منطقية منسلسلة. ع. عدد التوصيات بالفيلم: يقصد به عدد التوصيات الواردة بكل فيلم. 
هـ وجود مصطلحات علمية صعبة: يقصد به وجود ألفاظ أو مصطلحات أو اختصار ات علمية قد يصعب على إسى المستهوفين من الريفيين استيعابها وفهمها بدون مساعدة من الآخرين أو بدعم التعليق بمزيد من التفسير و الثنرح.

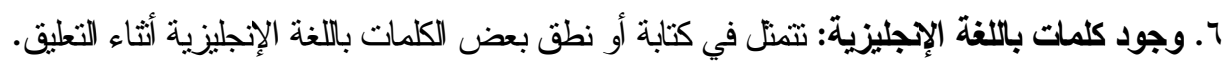

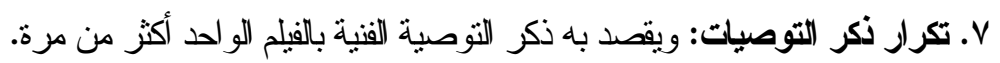
1. اكتمال التوصية بالفيلم: يقصد به ذكر النوصبية كاملة بلون نقصان. 9 . مصدر المادة العلمية بالفيلم: ويقصد به من نتسب إليه المادة للعلية بالفيلم وهو (هبئة تتفينية أو بحثية).

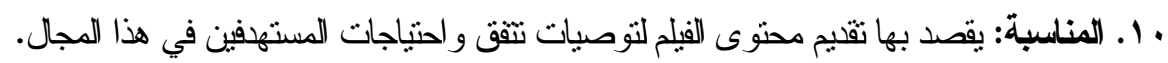

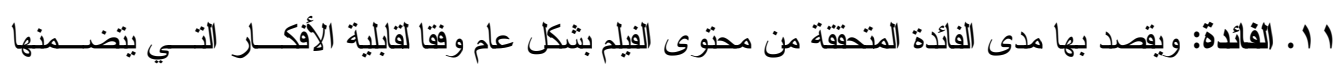
المحتوى للنطبيق بما ينقق و إمكانيات وقرر ات المستهوفين من عدمه.

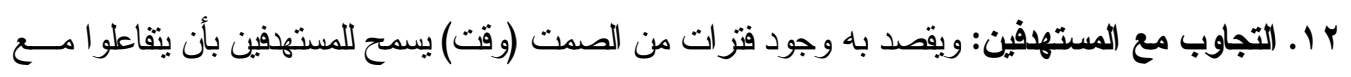
مشهد أو معلومة معينة من عدمه. r ا. وجود ملخص من عدمه في أخر الفيلم.

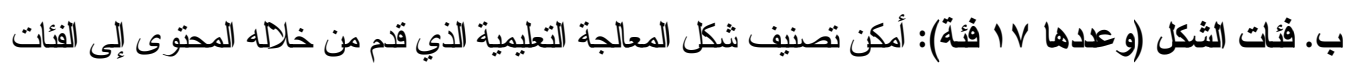
التالية: ا ـ شكل المؤثرات المستخدمة: تعددت أثنكال المؤثزات التي تشمل فئتي (أمنال شعبية- عمليات فنية بالمونتــاج

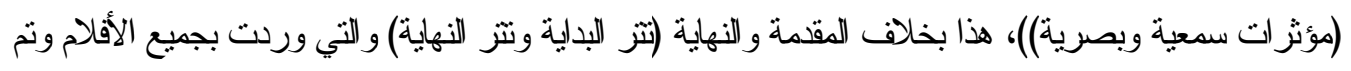
استبعادها من التحليل. r. تخطي بعدي الزمان والمكان في تقليم المطومات من عدمه.

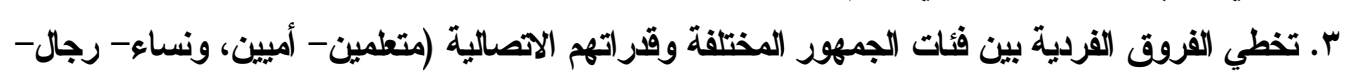
شباب) في استقبال المعلومات.

ع ـ مناسبة محتوى الرسالة التعليمية بالفيلم للقيم والعادات والتقاليل السائدة في الريف المصري من عمده.

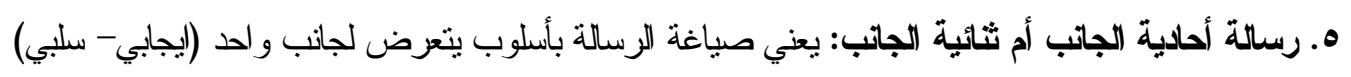

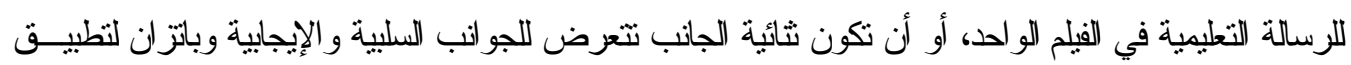
الثوصية.

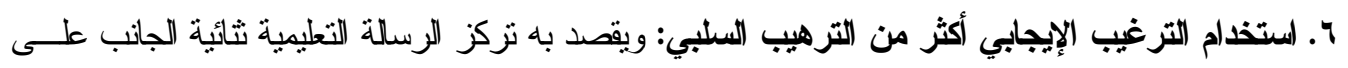

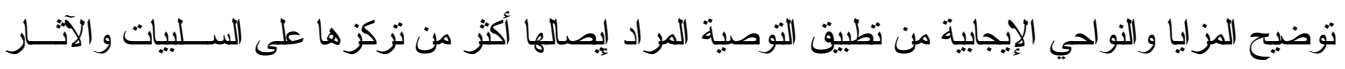
الضارة من عدم تطبيقها. V. استخدام الاستثارة العاطفية في مقابل التخاطب العقلالي: ويقصد به تزكز الرسالة التعليمية علـى اســتخدام

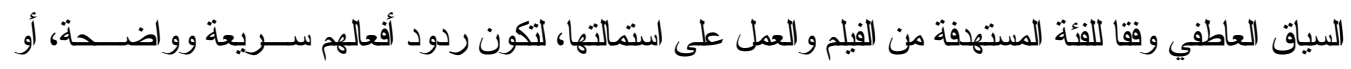

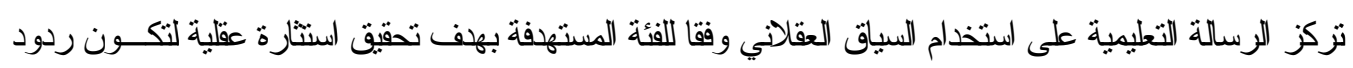
أفعالهم و استجابتهم منطقية. ^. شكل السياق: يقصد به التعليق على المحتوى من (معلق واحد- تبادل التعليق بين أثثين - أكثز من أثتـين)، وعدد مرات تكرار ورود أي شكل من أثنكال السياق السابقة الذكر. 
9 9. تواجد الرسوم التعليمية التوضيحية: يقصد بالرسوم مجموعة الأشكال التي تم رسمها بواسطة الليد أو التـي

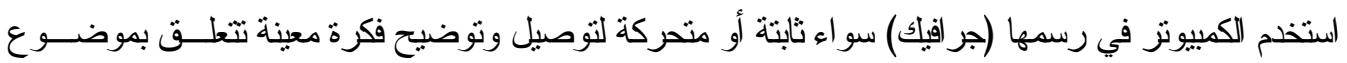
الفيلم، كما تم تقسيمها إلى أفلام بها رسوم تطليمية توضيحية و أفلام لا توجد بها. • 1 . تواجد الصور التعليمية التوضيحية: يقصد بها مجموعة الصور الفونوجر فية الثابنة المســتخدمة لإيضــاح

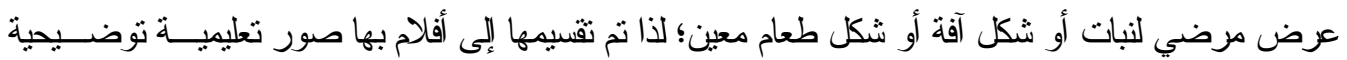
و ؤفلام لا توجد بهاصور تعليمية توضيحية. 11 ـ تواجد العلامات التطليمية: ويقصد بها مجموعة الأشكال و الصور والرموز حاملة المعنى سواء أكانت ثابتة

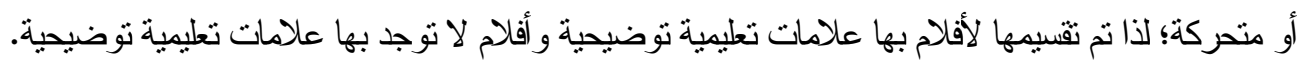

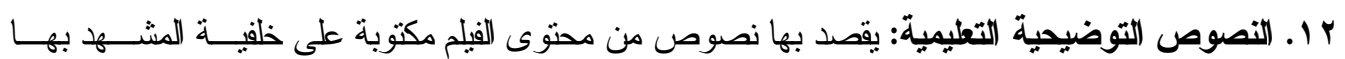

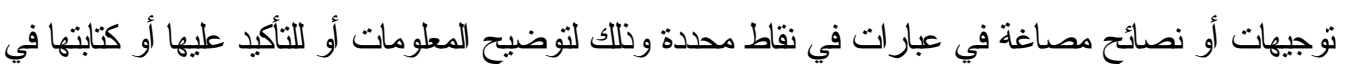

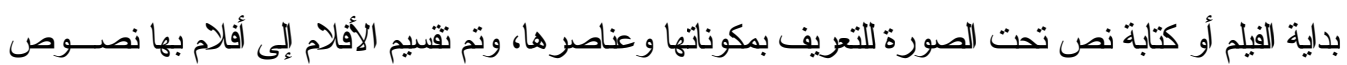
توضيحية وأفلام لا توجد بها.

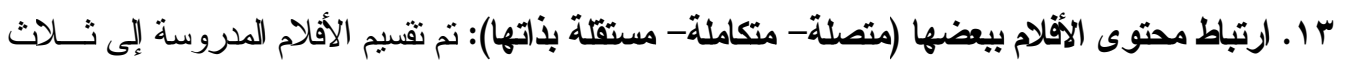

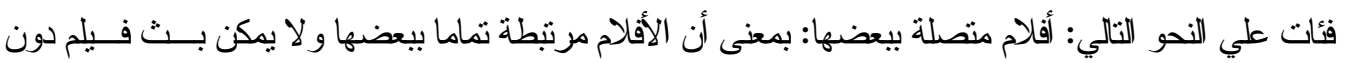

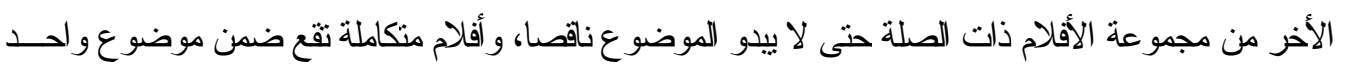

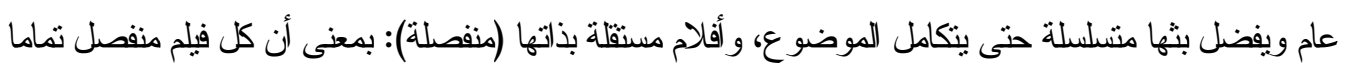
عن باقي الأفلام، ويمكن أن ييث بلا حاجة إلي محتوى ما قبله أو ما بعده من الأفلام.

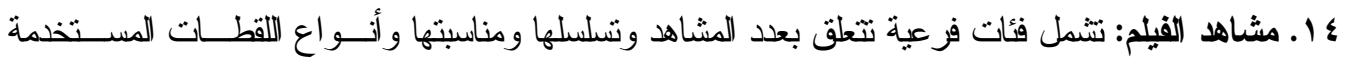
و استخدام التصوير البطئ. ويقصد بنسلسل المشاهد وجود علاقة سبيية بين المشهر الحالي والمشهر الســابق لـهـ

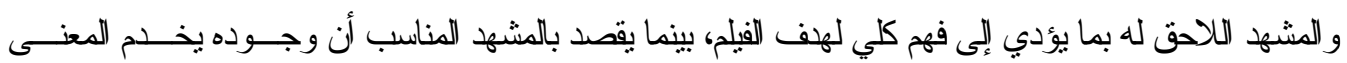

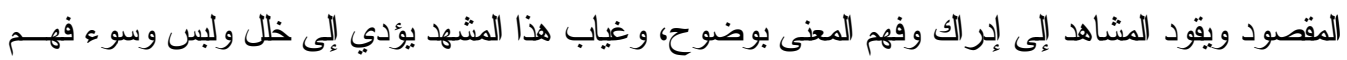

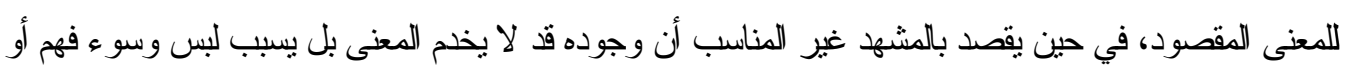

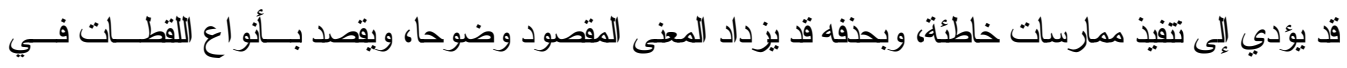

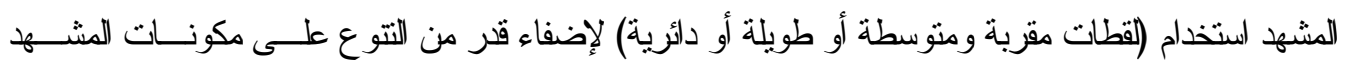

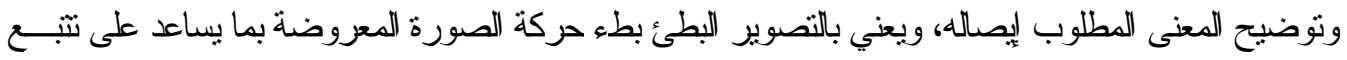

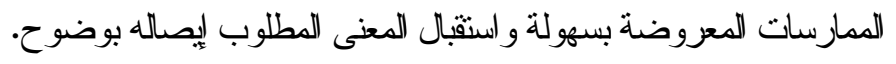

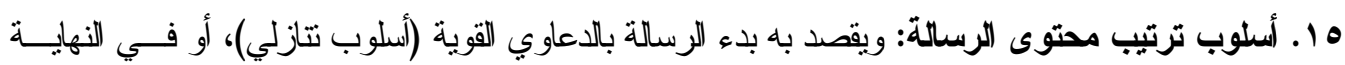

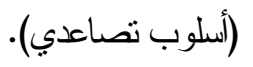

17 . 17

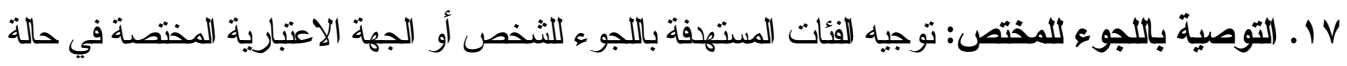

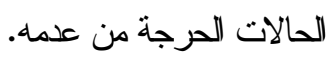

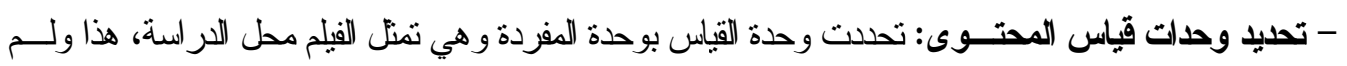
يقتصر البحث في تحليله على وحدة واحدة فقط وهي الفيلم كوحدة كبيرة وأساسية وإنما أمكن استخدام أكثــر مــن فئن 


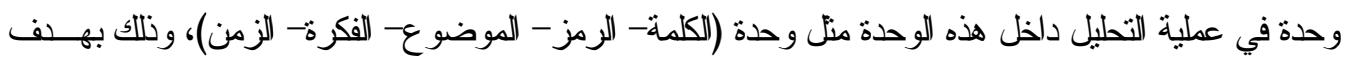

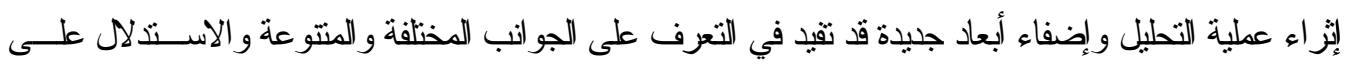

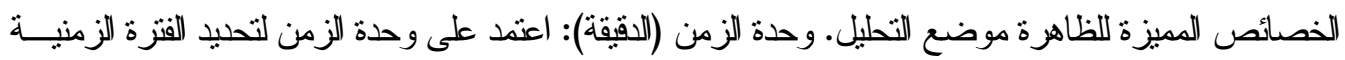

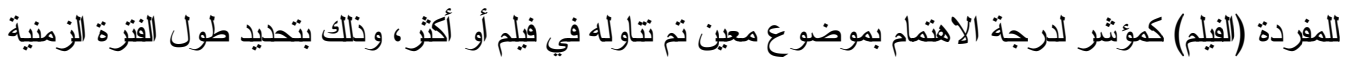
التي استغرقها بث هذا الموضوع إجمالا.

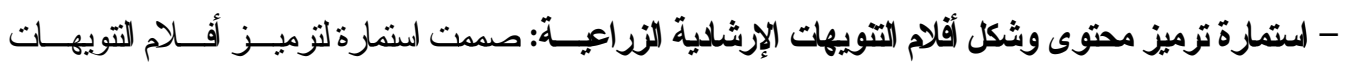

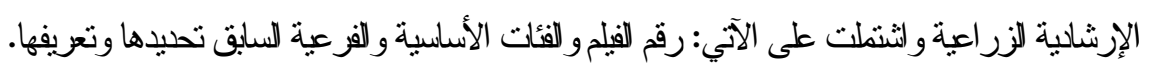

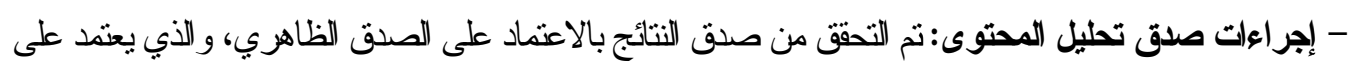

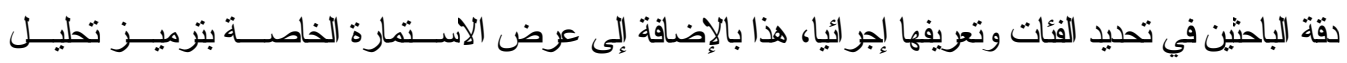
المضمون (المحتوى) و التعريفات الإجرائية لفئات التحليل على عدد من الأساتذة والهتخصصين في لالمجال للحكم

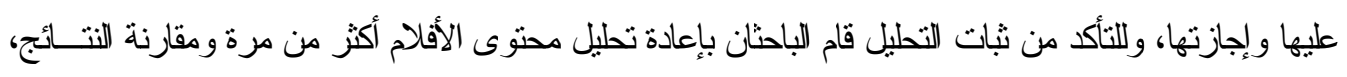

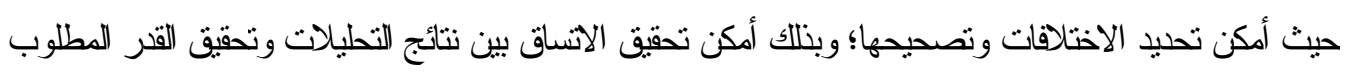
من الموضوعية، هذا وقد احتوت استمارة نزميز تحليل المضمون (المحتوى) على: رقم الفيلم والزمن الكلي للفيلم

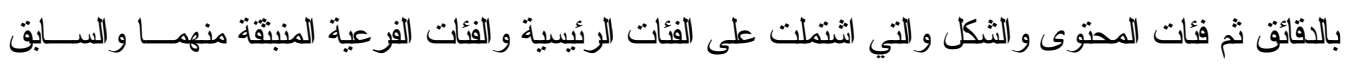
تعريفها.و واستخدم في النحليل الإحصائي التكرارات و النسب المئوية ومعامل ارتباط الرتب لسبيبرمان.

\section{النتائج ومناقشتها}

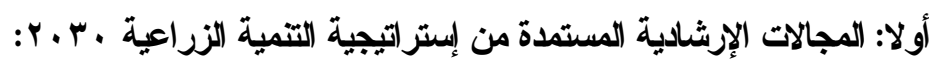

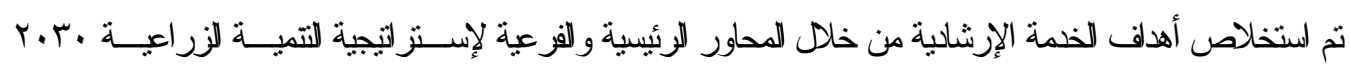

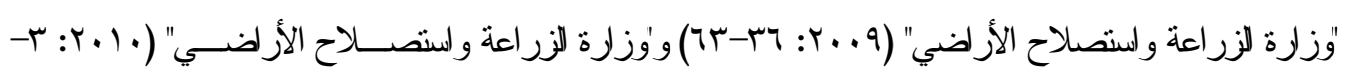

$$
\text { 9) وكانت على النحو التالي: }
$$

1- نتجيع وتعريف وتعليم الريفيين بكيفية الاستخدام الأمتل للمو ارد الزر اعية الطيعية من خلال خمسة عثر هدفا

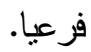

r- زيادة الإنتاجية الزر اعية لوحدتي الأرض و المباه من خلا ثناثة عشر هلفا فرعيا.

$$
\text { ب- تحقيق مرجة أعلى للأهن الغذائي من سلع الغذاء الإسنز انتيجية. }
$$

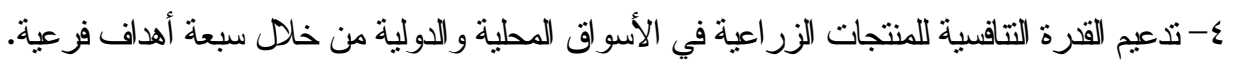

ه- تحسين مناخ الاستثمار الزر اعي من خلال ستة أهداف فرعية.

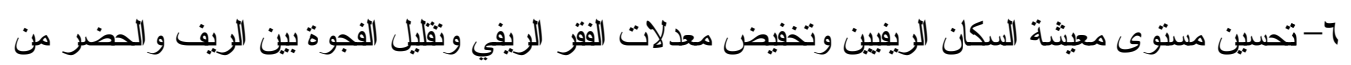
خلا سبعة أهدلف فرعية التمت بالعمومية و الثنمول.

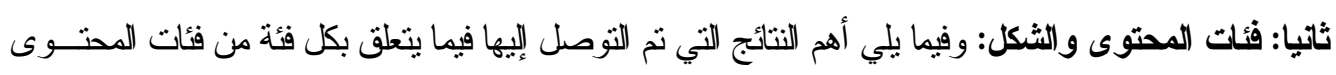
و النشكل:

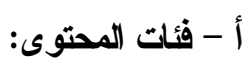
ا- مجال القيلم: وفقا لنتائج تحليل المحتوى الواردة بالجدول رقم (1) تضندنت الأفلام محـل اللراســـة أربعــة

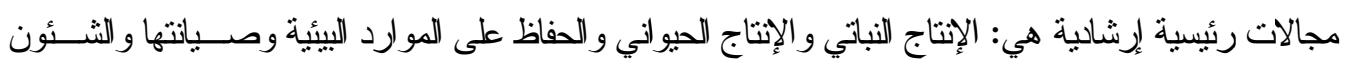


العامة، وذلك بحساب علد الأفلام لكل مجال و للنسبة المئوية لعدد الأقلام التي ورد بها كل مجال منسوبا إلى العدد

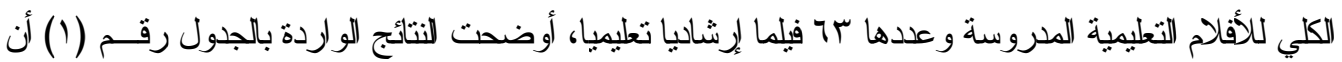

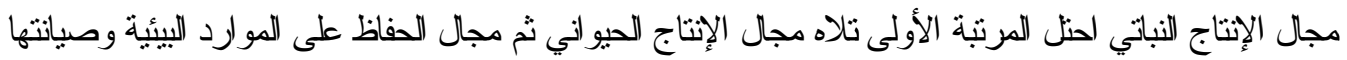

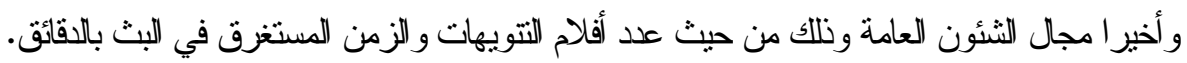

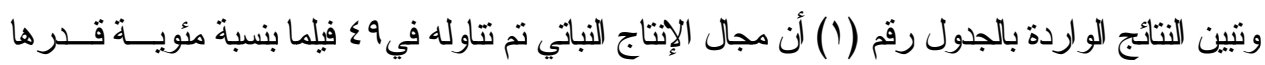

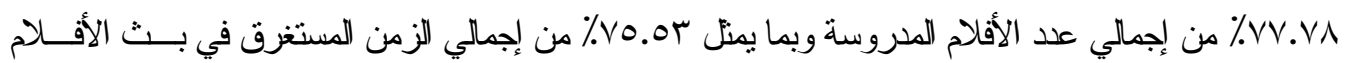

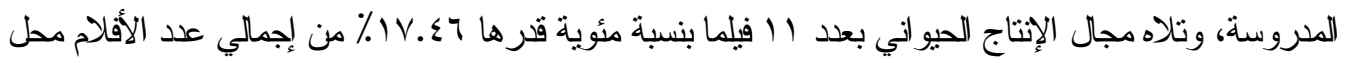

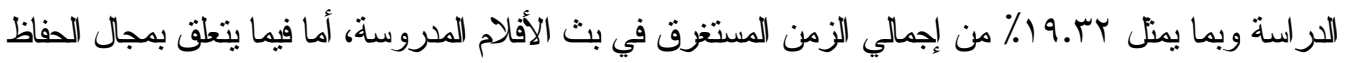

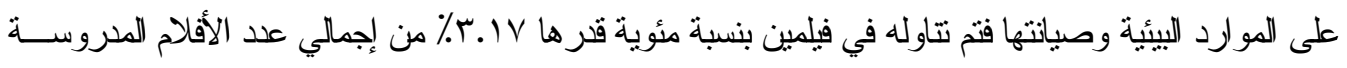

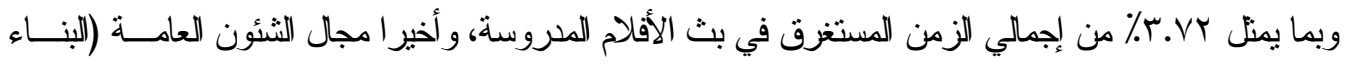

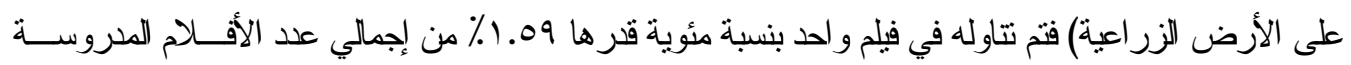
وبما يمنل سع. ٪ من إجمالي الزمن المستغرق في بث الأفلام المدروسة.

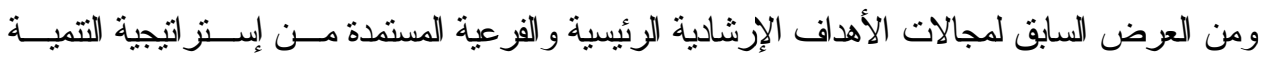

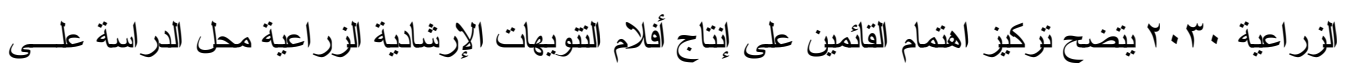

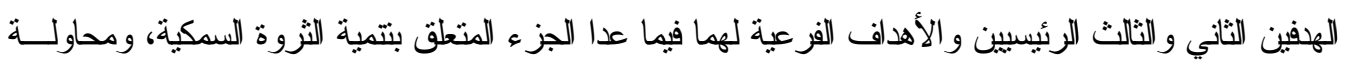
تحقيق بعض الأهداف الفرعية في بقية الأهداف الرئيسية الأول و الر ابع والخامس و السادس، بما بيتلزم معله النظر في المحتوي التعليمي لأفلام التتويهات في المراحل القادة بما بينقق وتحقيق الأهداف المستددة من الإنتر التيجية. جلول رقم (1): العلد والنسبة المئوية والزمن المستغق لعرض المحتوى التعليمي لفئات المجالات الزراعية

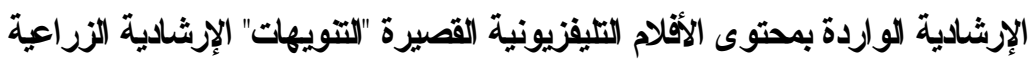

\begin{tabular}{|c|c|c|c|c|c|c|}
\hline التزتيب & $\%$ & الزمن المستغرق في العرض بالنقائق & الترتيب & $\%$ & علد الأكلام & 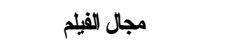 \\
\hline 1 & vo.0r & $11 r .1 \%$ & 1 & $v v_{. V \Lambda}$ & $\leq 9$ & - \\
\hline$r$ & $19 . r 5$ & rA. $\varepsilon Y$ & $r$ & $1 V . \& 7$ & 11 & - إتتاج حيواني \\
\hline$r$ & r.vr & $0 . \pi T$ & $r$ & r.IV & $r$ & - الحفلظ على العورد الييئية \\
\hline$\varepsilon$ & I. & r... & $\varepsilon$ & 1.09 & 1 & - شئون عامة \\
\hline & $1 \ldots$. & $1 \leqslant \Lambda$. TO $^{\circ}$ & & $1 \ldots \ldots$ & rי & المجموع \\
\hline
\end{tabular}

إجمالي عدد الأفلام المدروسة سا فيلما

وبحساب معامل ارنباط الرنب لسييرمان بعد تزتيب مجالات الأفلام المدروسة حسب عدد مرات ورودهـــا

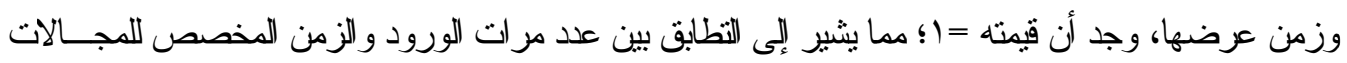

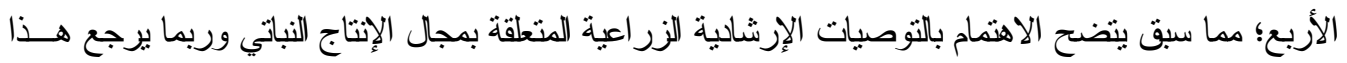

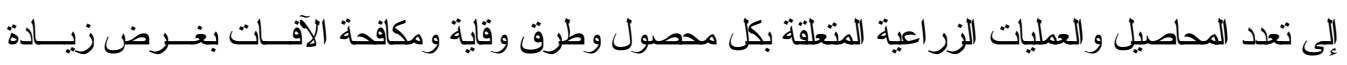
الإنتاجية وبخاصة من المحاصيل الرئيسية الإستر اتيجية.

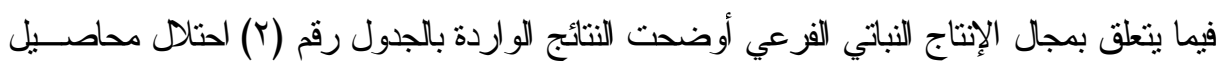

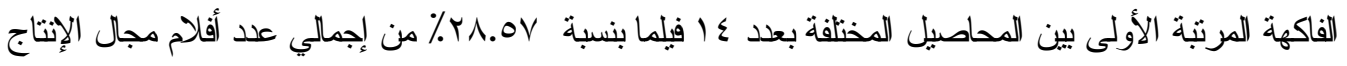

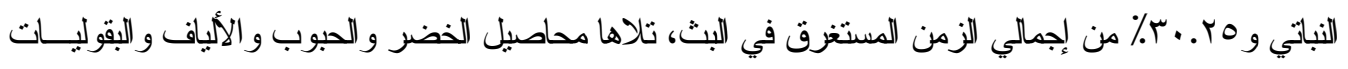

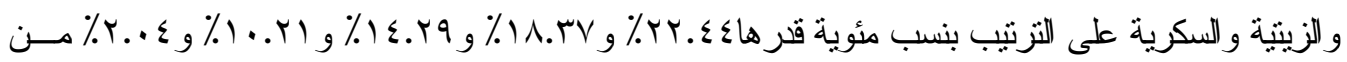




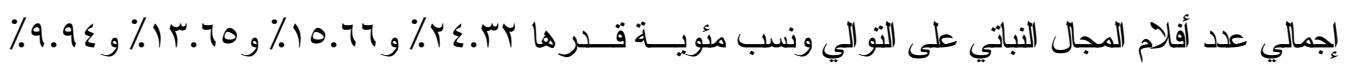

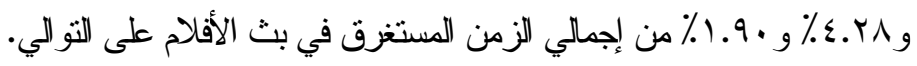

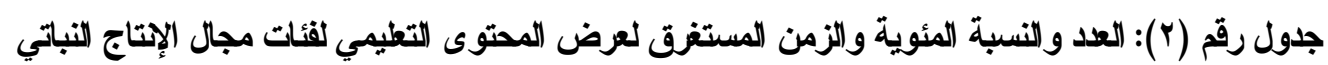

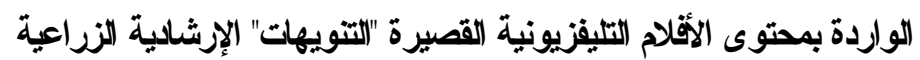

\begin{tabular}{|c|c|c|c|c|c|c|}
\hline الترتيب & $\%$ & الزمن الستغرق في العرض باللقاتق & التزتيب & $\%$ & عد الأقلام & مجال القيلم \\
\hline$r$ & r纟.rT & $r v .1 \Lambda$ & $r$ & Yr.s纟 & 11 & - محلصيل الخضر \\
\hline$r$ & 10.77 & IV.rE & $r$ & IA.rV & 9 & - محلصيل الحبوب \\
\hline 1 & r..ro & Tr.ov & 1 & YM.OV & $1 \leq$ & - محلصيل الفكهة \\
\hline$\varepsilon$ & 15.70 & 10.19 & $\varepsilon$ & $1 \leq .49$ & $\mathrm{v}$ & - محلصيل الأيلف \\
\hline 0 & $9.9 \Sigma$ & $11 . .9$ & $\circ$ & $1 \cdot . r 1$ & 。 & - محلصيل البقوليت \\
\hline 9 & \&.YA & $\varepsilon . \S \wedge$ & 7 & $\varepsilon . . \wedge$ & $r$ & - محلصيل الزيتية \\
\hline$v$ & 1.9. & r... & $\mathrm{v}$ & r.. & 1 & - محلصيل السكرية \\
\hline & $1 \ldots \ldots$ & $11 r .1 \%$ & & $1 \ldots$. & $\leqslant 9$ & المجموع \\
\hline
\end{tabular}

إجمالي عدد أفلام مجال الإتناج النباتي 9 ؛ فيلما

وبحساب معامل لرنباط الرتب لسبيرمان بعد نزنيب أفلام المحاصيل بمجال الإتتاج النباتي حسب عدد مرات

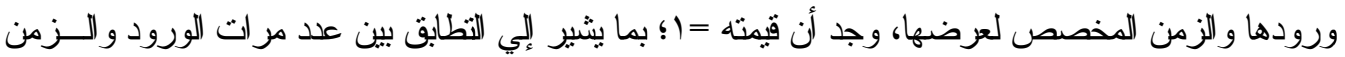
المخصص لفئات المحاصيل السبع. تتشير التنائج الواردة بالجدول رقم (ץ) إلى احتلال الفئة تحت فرعية المانثية المرتبة الأولى بمجــال الإتتــاج

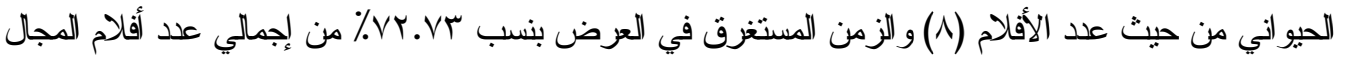

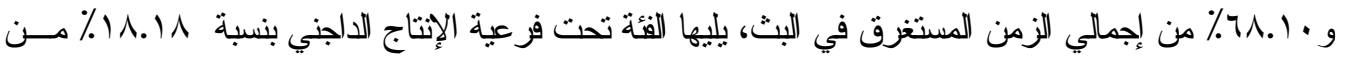

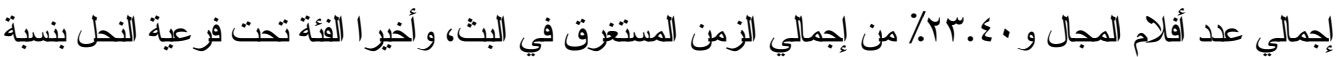

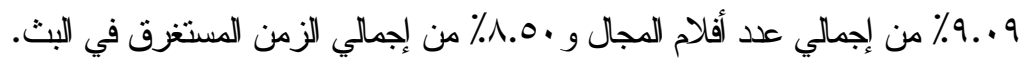

جدول رقم (ץ): العلد والنسبة المئوية والزمن المستغق لعرض المحتوى التعليمي لفئت مجال الإتاج الحيواني

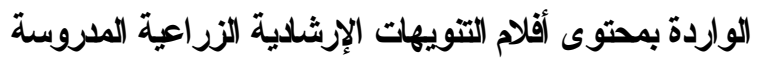

\begin{tabular}{|c|c|c|c|c|c|c|}
\hline الترتيب & $\%$ & الزمن المستغق في العرض بلالقلثق & الترتيب & $\%$ & عد الأقلام & مجل القيلم \\
\hline 1 & 71.1 & $19 . \mathrm{r}$ & 1 & VY.VY & $\Lambda$ & - - ملثية \\
\hline r & rr.s. & $7 . \varepsilon T$ & r & $1 \wedge .11$ & r & 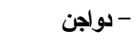 \\
\hline$r$ & 1.0. & r.M & $r$ & $9 . .9$ & 1 & - نحل \\
\hline & $1 \ldots \ldots$ & YA.\&Y & & $1 \ldots \ldots$ & 11 & المجموع \\
\hline
\end{tabular}

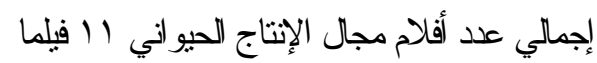

وبحساب معامل ارتباط الرنب لسبيرمان بعد نزتيب الأفلام الواردة بمجل الإثتاج لحيواني حسب عدد مرات

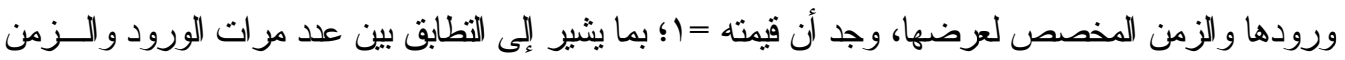
المخصص اللفئات التحت فرعية الثناث. ץ- المساحة الزمنية للمحتوى التعليمي بالفيلم: نوضح نتائج تحليل المحتوى بالجلول (ع) أن كل أفلام النتويهات

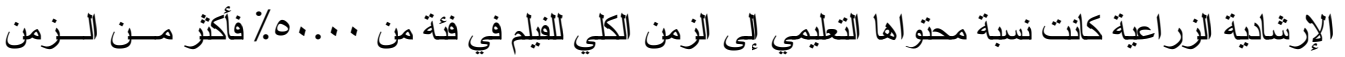

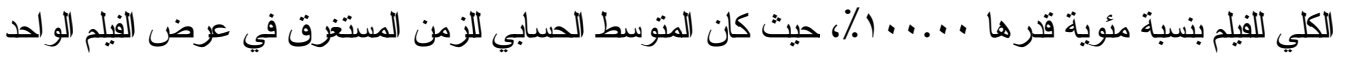

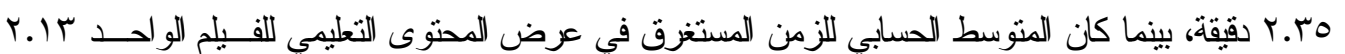


لقيقة، وبذا كان المتوسط الحسابي لنسب الزمن المستغرق في عرض المحتوى التعليمي للأفلام إلـى المجمــوع

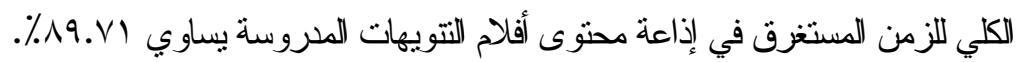
جلول رقم (؛): العلد والنسبة المئوية لأكلام التتويهات الإششلاية الزراعية وفقا للنسبة المئوية لزمن المحتوى التطليمي إلى الزمن الكلي للقيلم

\begin{tabular}{|c|c|c|}
\hline$\%$ & علد الأكلام & فئت النسبة المئوية لزمن المحتوى التطليمي الأقلام \\
\hline$\ldots$ & . & - من صفر \% إلى أقلّ من ه \% من الزمن الكلي \\
\hline $1 \ldots \ldots$ & זי & - من \% فكثر من الزمن الكلي \\
\hline $1 \ldots .$. & 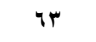 & المجموع \\
\hline
\end{tabular}

إجمالي عدد الأقلام المدروسة سד فيلما

وتتثير هذه النتائج إلى الاهتمام بالمحتوى التعليمي للأفلام، حيث شكل أغلب الفزرة الزمنية للفيلم وبمعالجـــة

تعليمية تهاف إلى إلمام المتتهلفين بمعظم جو انب التوصيات الفنية بما بساعد على قبولها.

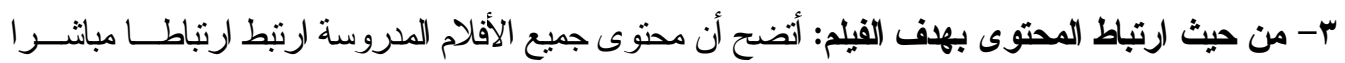

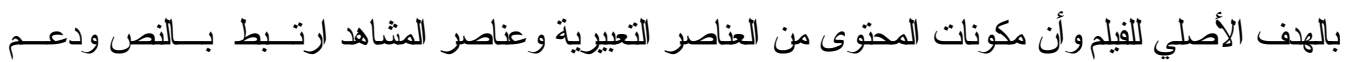

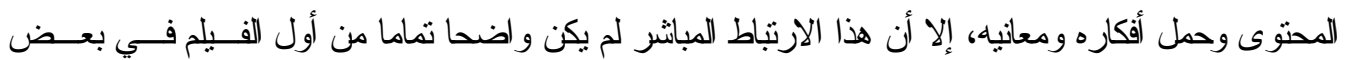

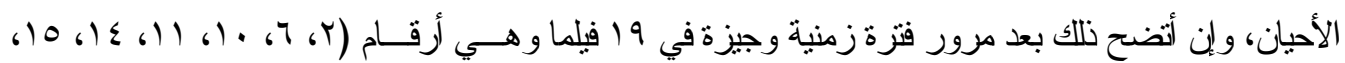

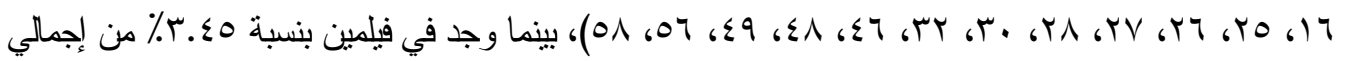

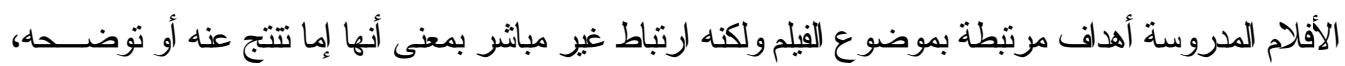
وقد أمكن حصر هذه الأهداف لغير مباشرة على النحو التلائ:

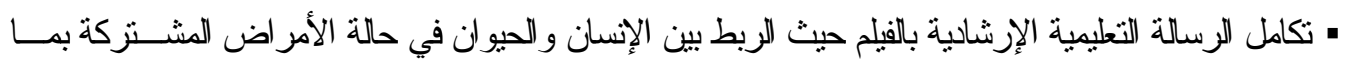
يوضح ويقرب للأذهان مخاطر إصابة العجول الرضيعة بمرض الإسهال كما ورد في الفيلم (r؟r).

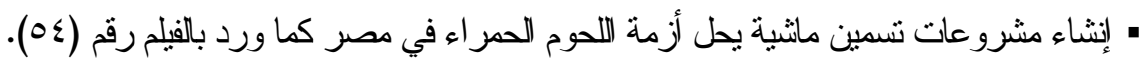

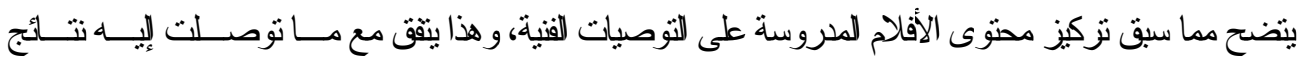

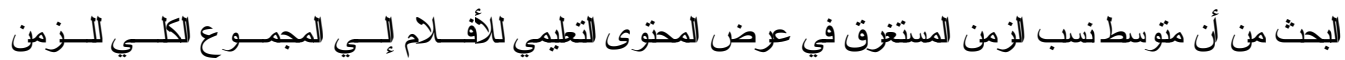

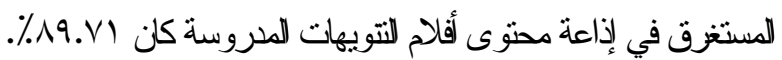

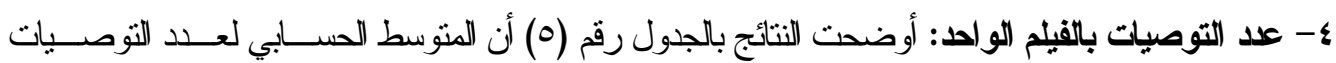

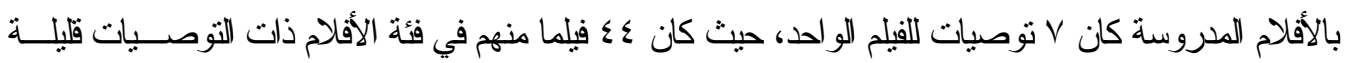

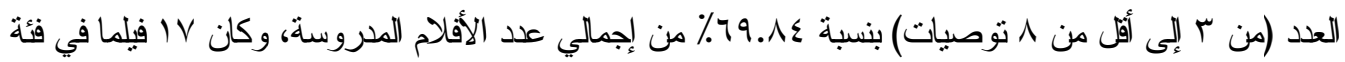

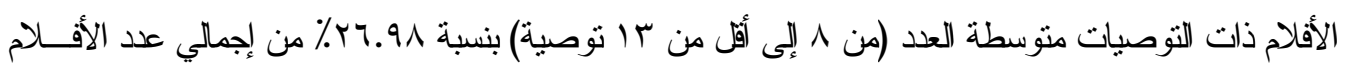

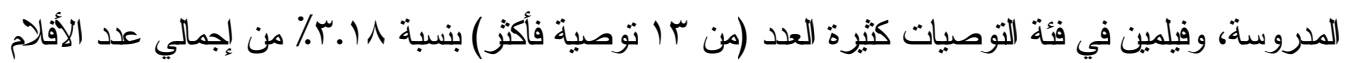
المدروسة. 
جلول رقم (•): العلد والنسبة المئوية والمتوسط الحسابي لأفلام التتويهات الإرشادية الزراعية تبعا لعلد التوصيات بالأفلام المدروسة

\begin{tabular}{|c|c|c|c|}
\hline المتوسط الحسلبي & $\%$ & عد الأقلام & الفئت \\
\hline \multirow{4}{*}{ 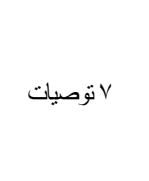 } & $79 . \wedge \varepsilon$ & « & 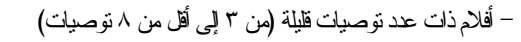 \\
\hline & r..91 & iv & - أفلام ذات عدد توصبات متوسطة (من ^ إلى أقل من كا توصية) \\
\hline & $r .11$ & r & - أفلام ذات عدد توصيات كثيرة (من س ا ا توصية فأكثز) \\
\hline & $1 \ldots \ldots$ & זי & المجموع \\
\hline
\end{tabular}

إجمالي الأقلام المدروسة سج فيلما

وتتشير هذه النتيجة إلى الجها المبذول في المعالجة التعليمية حيث يتم تتاول أنسـب عـــد مــن التوصــيات الإرشادية الفنية العرنبطة بموضوع الفيلم لينسنى نتاول معظم جو انب الموضوع ولى وققا للزمن المتاح.

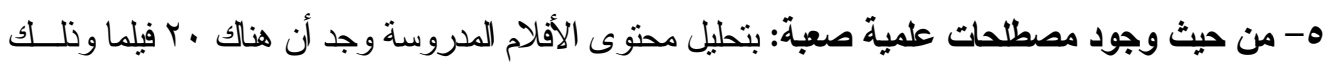

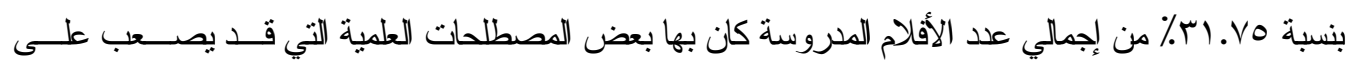

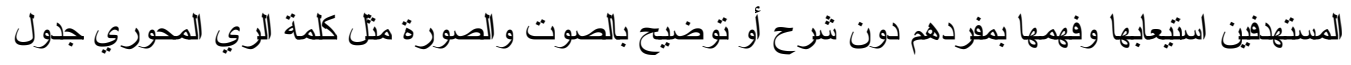
رقم (ا) ، وعفن الجذور الفيوزيرمي و الثيران أو الأجرل، والأمراض الفيروسية، والمبيدات الجهازية والعناصر

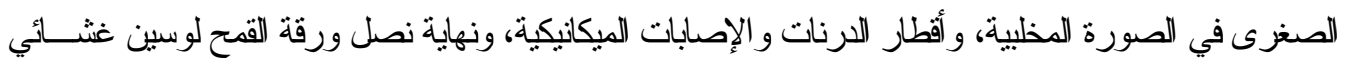

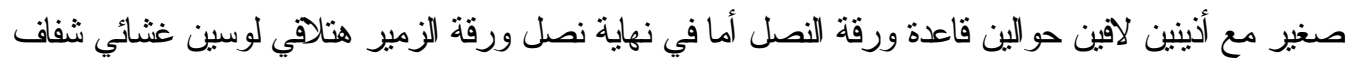

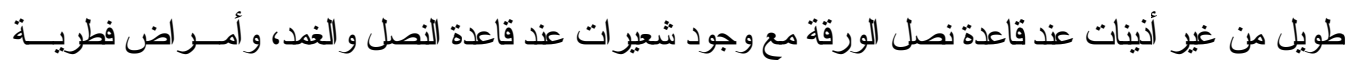

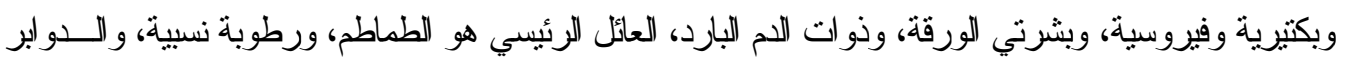

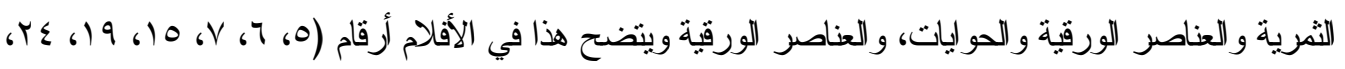

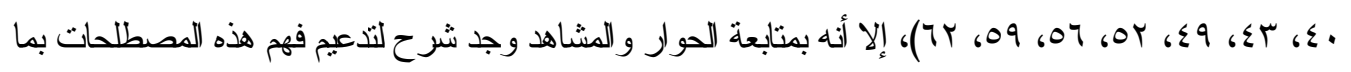

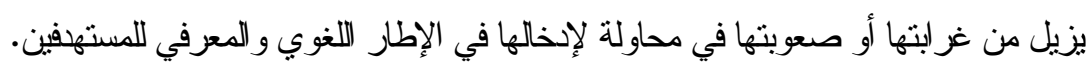
في حين أنه في الأفلام أرقام (r، 0، 9، سه) لم يتم هذا التوضيح خاصة فيما يتعلق بوحدات الآزوت، هذا

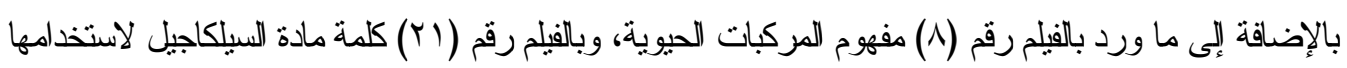

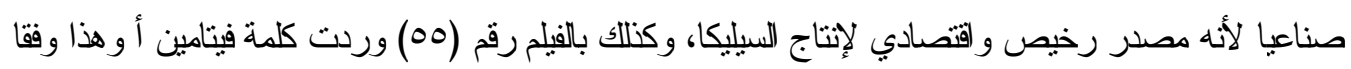

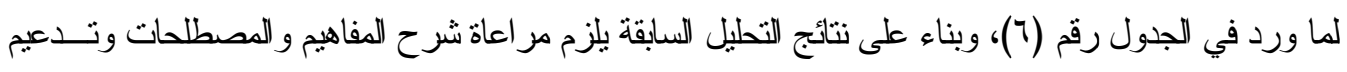

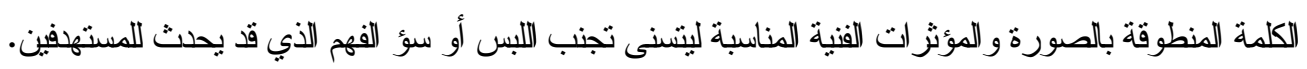
جلول رقم (ج): العلد والنسبة المئوية لألام التتويهت الإرشلاية الزراعية تبعا لوجود مصطلحات علمية صعبة، وكلمات

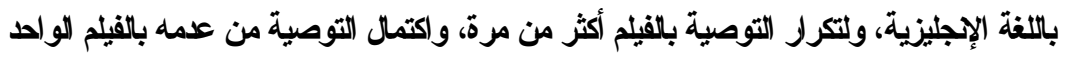

\begin{tabular}{|c|c|c|}
\hline$\%$ & العلد & الفئات \\
\hline M.Vo & $r$. & - وجود مصطلحات علمية صعبة \\
\hline V..$\leq$ & 0 & - وجود كلمات باللغة الإنجليزية \\
\hline $79.7 \mathrm{~V}$ & $\varepsilon r$ & - نكرار التؤصية بلفيلم أكثز من مرة \\
\hline ro.9r & 17 & عدم اكثمل التوصية بالفيلم الو لحد \\
\hline
\end{tabular}

إجملي عدد الأفلام المدروسة سا فيلما، * حسبت النسبة المئوية لإجمالي مجموع الأفلام المدروسة. 


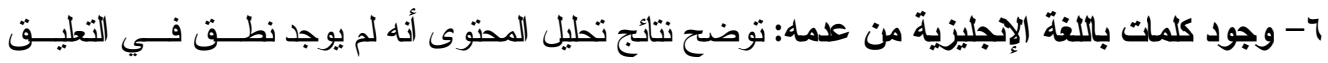

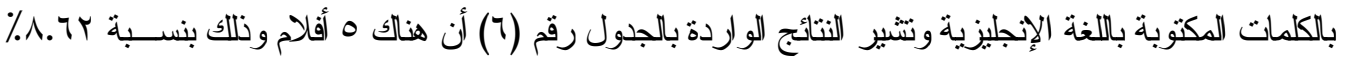

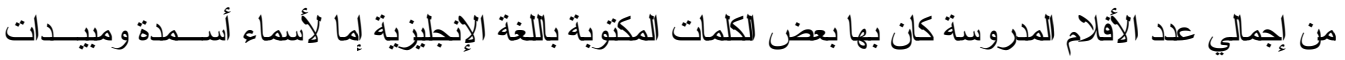

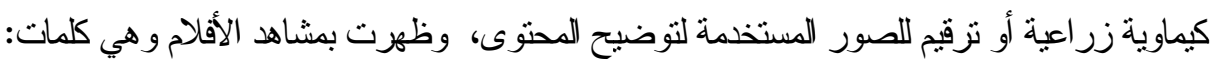
Biological Insecticide from bacillus

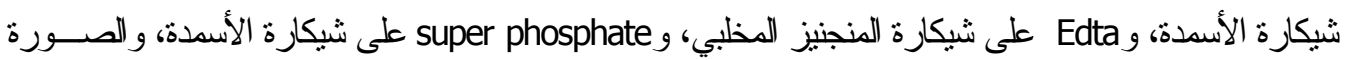

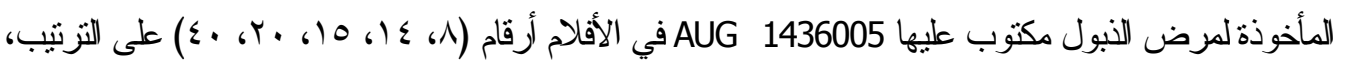

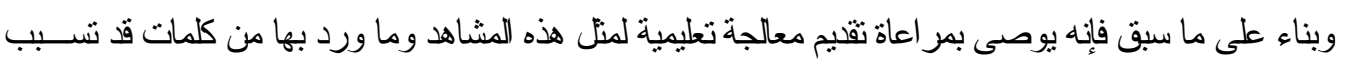

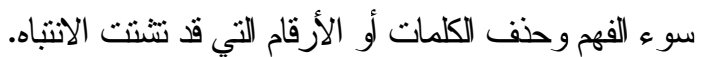

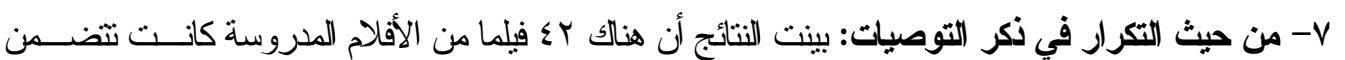

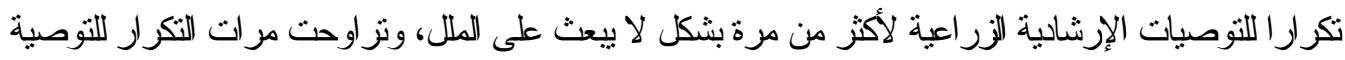

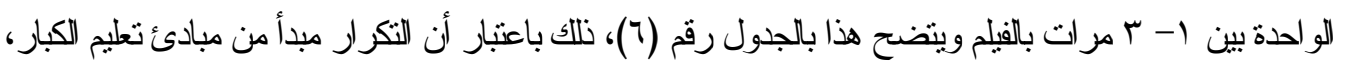
ويساعد على نثيت الفكرة وتحقيق الفهم لدى الفئات المستهافة؛ كما يعد وسيلة من وسائل الثأثير و الإفناع.

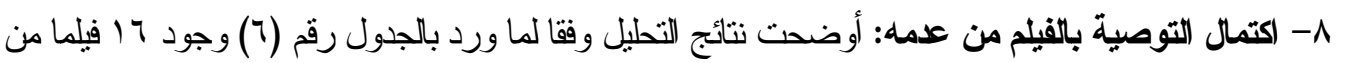

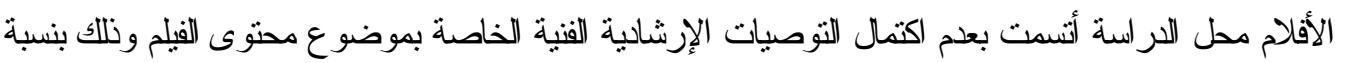

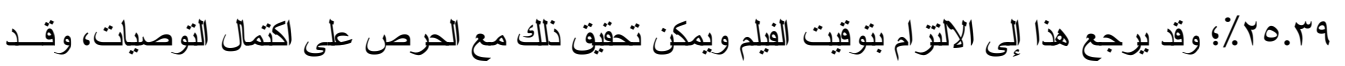

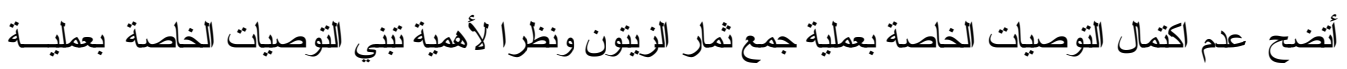

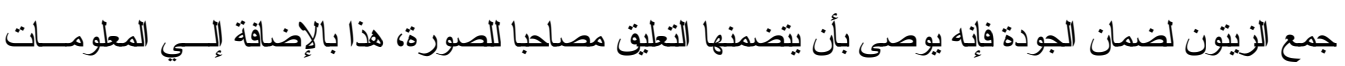

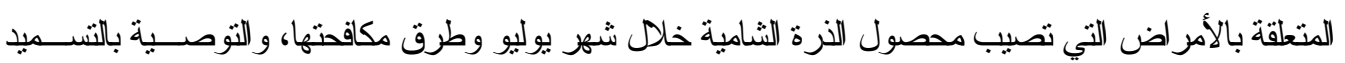

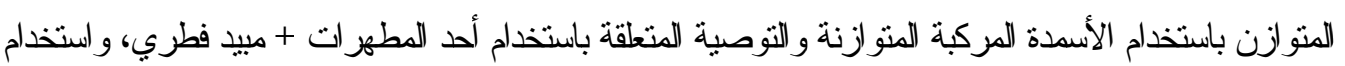

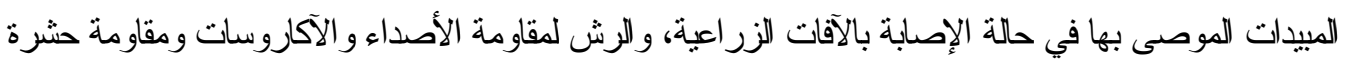

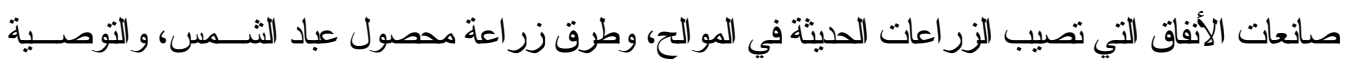

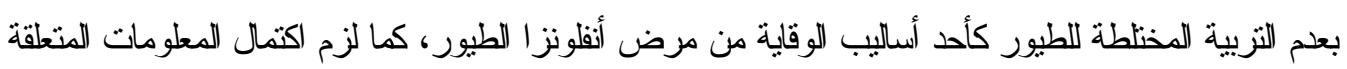

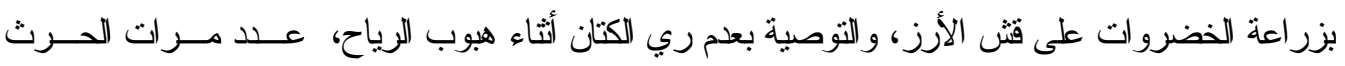

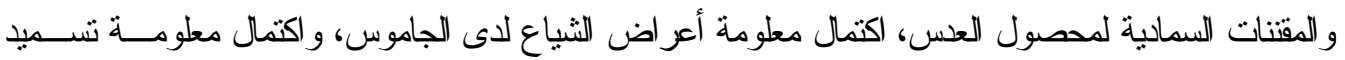
الثثعبر بالإثارة إلى ميعاد الففعة الثالثة للتسميد الآزوتي، والتوصية بالاستمر ار في مقاومة ذبابة الفاكهة لمحاصيل

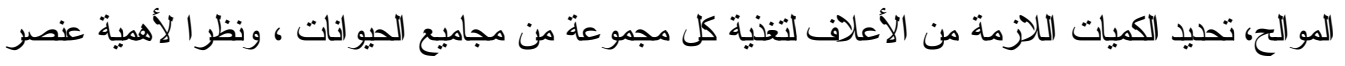

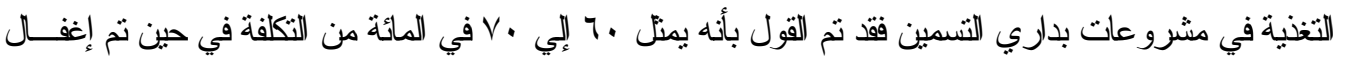

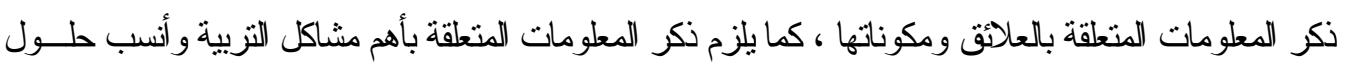

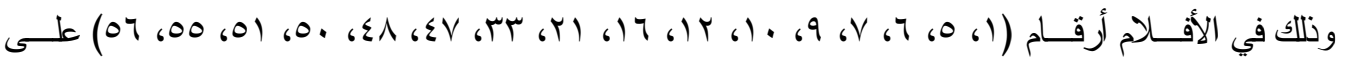
النزتيب.

9- مصدر المادة الطمية بالفيلم: أتضح أن مصدر المادة العلمية لمحتوى جميع الأفلام المدروسة كانـــ الإدارة

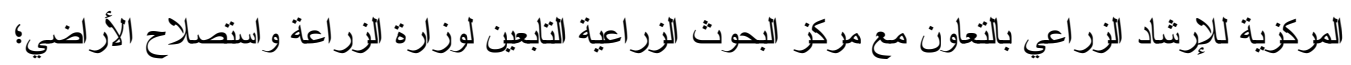


وأن المادة المصورة في معظمها كانت مما سبق تصويره أثناء إنتاج حلقات البرنامج الإرشادي التعليمسي 'ســر الأرض".

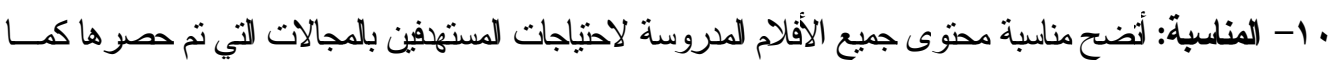

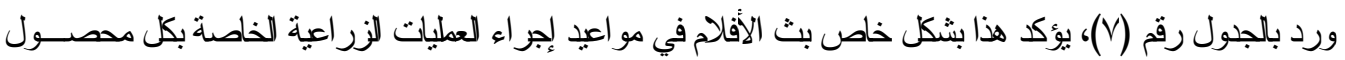

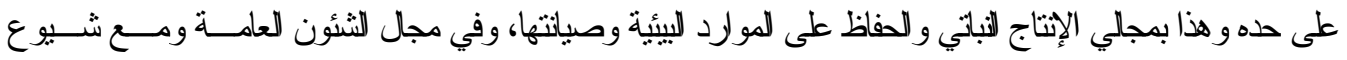

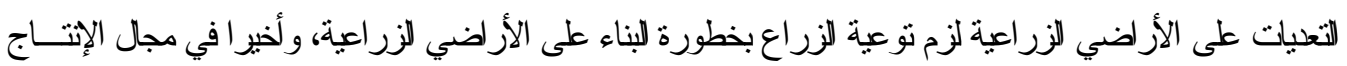

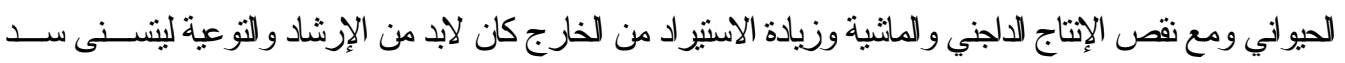
العجز وتحقيق الاكثناء للانتي.

جدول رقم (V): العدد ولنسبة المئوية لأقلام التتويهات الإرشلدية الزراعية وفقا لمنلسبة محتوى الأقلام لاحتياجات المستهوفين

\begin{tabular}{|c|c|c|}
\hline$\%$ & عد الأقلام & فنات منلسبة المحتوى لاحتيلجات الستتهفين \\
\hline $1 \ldots \ldots$ & זי & - منلب \\
\hline$\cdots$ & . & 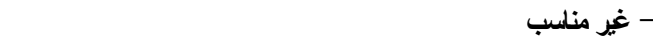 \\
\hline $1 \ldots \ldots$ & ז & 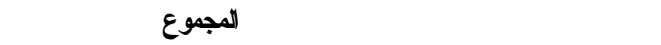 \\
\hline
\end{tabular}

إجمالي عدد الأفلام الدروسة با فيلما.

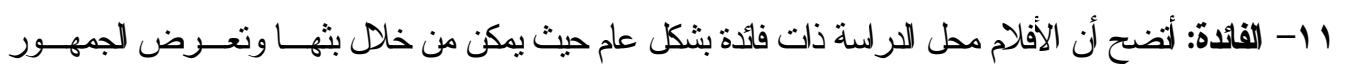

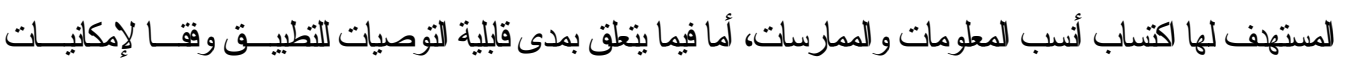

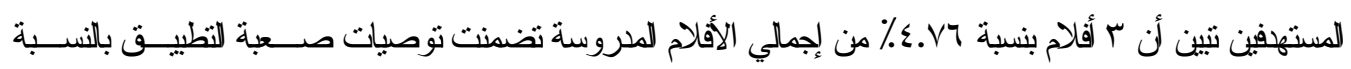

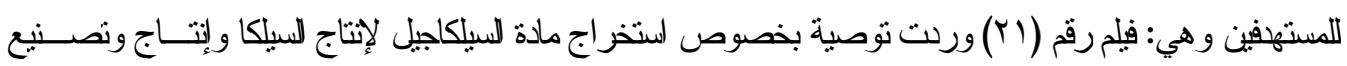

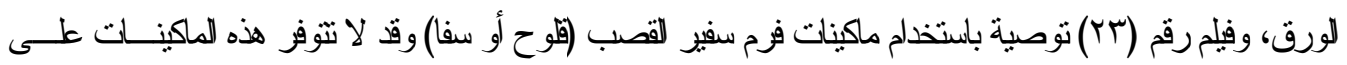

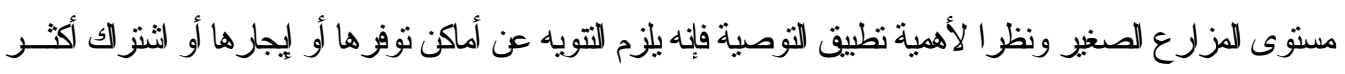

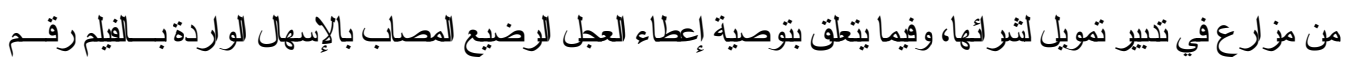

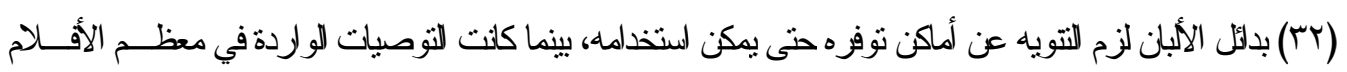

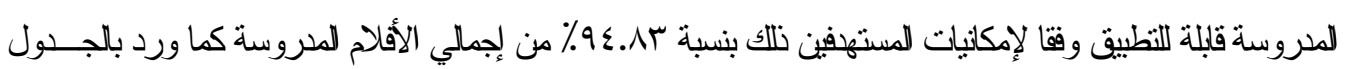

رقم (^)

جدول رقم (^): العد والنسبة المئوية لأفلام التتويهات الإرشلاية الزراعية وفقا للفائدة من الأفلام

\begin{tabular}{|c|c|c|}
\hline$\%$ & عد الأقلالم & فئات الفلدة \\
\hline $1 \ldots$. & r & - يفيد \\
\hline$\cdots$ & • & - لا يفيد \\
\hline $1 \ldots$. & r & 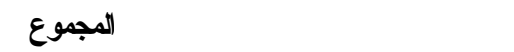 \\
\hline \multicolumn{3}{|c|}{ قلبلية الأككار التي يتضمنها الحتوى للتطيق وفقا لإكليات المستهفين } \\
\hline $90 . \Gamma \varepsilon$ & 7. & 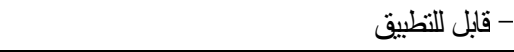 \\
\hline$\varepsilon . \vee ५$ & $r$ & - غير قابل للتطييق \\
\hline $1 \ldots \ldots$ & r & المجموع \\
\hline
\end{tabular}

إجمالي عدد الأفلام للدروسة بح فيلما. 


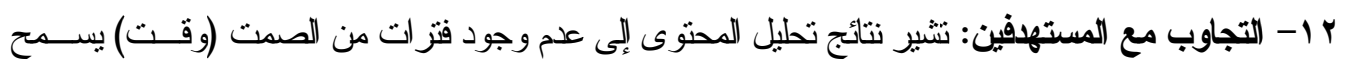

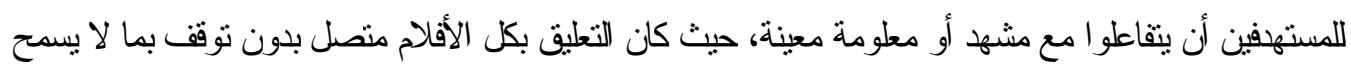

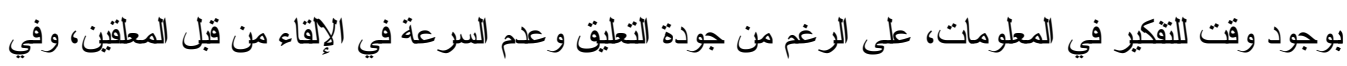

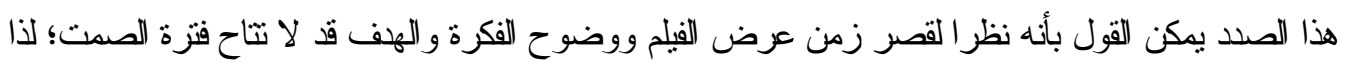

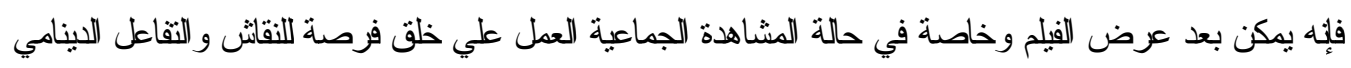
بين المستهوفين المرتمين. r 1 - وجود ملخص من عمه في نهاية الفيلم: أتضح من نتائج تحليل المحتوى عدم وجود ملخص في نهاية كل

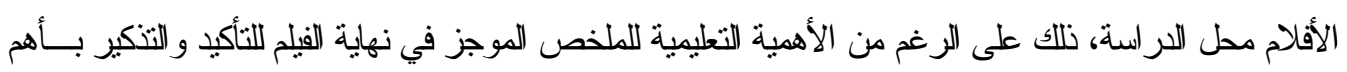

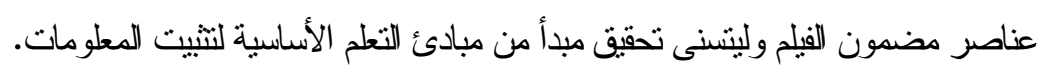
جدول رقم (9): أقلام التتويهات الإرشادية الزراعية محل الدراسة وزمن محتوى القيلم (لتعليمي/ الكلي)

\begin{tabular}{|c|c|c|c|c|}
\hline$* \% \%$ & الزمن الكلي للقيلم & زمن المحتوى & 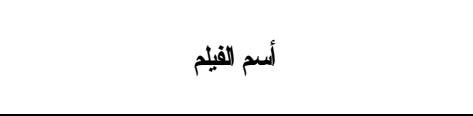 & رقم القيلم \\
\hline vi.Ir & $1 . . v$ & .01 & خلمة ثٔنجار الزيتون خلا شهر أكتوير & .1 \\
\hline$v V . .1$ & $1 . r v$ & $1 . . v$ & العليات اللزمة لمحصول الأرز خلال شهر يوليو &.$r$ \\
\hline $94.1 \mathrm{~V}$ & r. $\leqslant 4$ & r.rr & زراعة محصول الثوم &.$r$ \\
\hline No.rv & r..r & $1 . \leqslant 0$ & الجني الحصن لمحصول القطن &.$\varepsilon$ \\
\hline$\Lambda \leqslant . \leqslant V$ & $1 . \leqslant r$ & $1 . \mathrm{rV}$ & خلا شهر يوليو الزيلية اللامة لمحصول النرة الثلمية & .0 \\
\hline $9 . .91$ & r.IT & r.. & زراعة مشلىل العوة الخريفي للطملطم & .7 \\
\hline $9 . .91$ & r. ז & r.r. & العمليت للزمة للفول البلدي خلا شهر ينائ &.$v$ \\
\hline Av.17 & $1 . \leqslant 9$ & $1 . \mathrm{ro}$ & والتلتيز اللامة لمحصول القطن في مرحلة التزهير &.$\wedge$ \\
\hline
\end{tabular}




\begin{tabular}{|c|c|c|c|c|}
\hline & & & \multicolumn{2}{|c|}{ تلبع جلول روم 9} \\
\hline$\% \%$ & الززمن الكلي للقيلم & زمن المحتوى التعليمي" & سمب الفيلم & روم الهيلم \\
\hline $10 . \wedge \varepsilon$ & $1.0 \mathrm{~T}$ & $1 . \mathrm{TV}$ & العمليت اللازمه لمحصول لكتلن خلا شُهر ينائي & .9 \\
\hline $91.9 \mathrm{~V}$ & Y.IV & Y.. Y & خلمة لَُجْل الموالح خلا شهر يوليو & $.1 \cdot$ \\
\hline $9 \vee . \leqslant \leq$ & $1.0 \mathrm{~V}$ & 1.07 & علامات نضج محصول القـح & .11 \\
\hline 99.99 & P.Tे & P.19 & زراعه محصول عبد التّس & .17 \\
\hline$\pi 9.19$ & $1 . \Gamma 9$ & 1.19 & 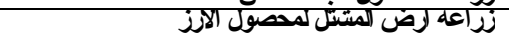 &.$\pi$ \\
\hline$\pi V . \wedge 9$ & T.TV & T.11 & 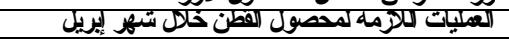 & $.1 \varepsilon$ \\
\hline qr.Yq & Y.६६ & r.rr & 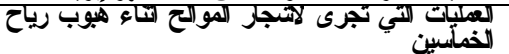 & .10 \\
\hline 10.20 & T.१० & T.श & آهلونزآلطيوز & .17 \\
\hline $91 . \mathrm{Vr}$ & T.1T & Y.. Y & ز زراعه محصول الفول السودلتي & $.1 \mathrm{~V}$ \\
\hline $9 Y .91$ & Y..V & 1.01 & خلمه محصول لأفول لسودادي في شُهر يوليو & .11 \\
\hline $90.7 \%$ & r.. & Y.00 & زراعة العروة الصيفية لمحصول آلبطاطس & .19 \\
\hline 91.41 & Y.0 & r.rq & تحميل البصل على القطن &. $\mathrm{r}$. \\
\hline 99.19 & $\frac{1.0 \%}{1.0}$ & 1.29 & حصد محصول الإزي & 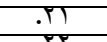 \\
\hline 19.19 & 9.11 & 1.05 & حصد المحاصيل الزيّيتية &.$\pi$ \\
\hline AV.YY & T.IT & $1.0 \xi$ & سفير القصب &.$T T$ \\
\hline AY.TI & 1.00 & $1 . \% 0$ & مكلقحة الزّمير في محصول القمح &.$T \varepsilon$ \\
\hline $91 . \leqslant \%$ & 1.50 & $1 . \mathrm{m4}$ & الطقيليات لخزجية في لحيواتك &. To \\
\hline $\mathrm{V \Lambda . \cdot V}$ & $1.0 \leqslant$ & $1 . \mathrm{rq}^{2}$ & رعاية العجلات للتشثل &.$\times 7$ \\
\hline A५.Y१ & Y.00 & Y.TI & رعايةً العجول الرضيعةة &. $\mathrm{TV}$ \\
\hline A.... & Y.I. & $1 . £ \leqslant$ & الحشرات القثرية في نفيل البالح| &. $\mathrm{r} \Lambda$ \\
\hline $9 \leqslant . V \leqslant$ & T.IT & Y.. T & العروة الثشتوية للطماطّة &. $\mathrm{rq}$ \\
\hline Vo.VA & Y.. A & $1 . \mathrm{rV}$ & اللبناء على الأزض الزراعية &.$\Gamma \cdot$ \\
\hline $94.9 \mathrm{~V}$ & Y.. A & 1.09 & التفعم السوطي لو قصب السكر & .4 \\
\hline $9 \% .1$. & Y.YO & Y.10 & الإسهال في لعجول الرضيعة: &. $\mathrm{TK}$ \\
\hline$\Lambda 1 . .0$ & 1.ro & $1.1 \mathrm{~V}$ & 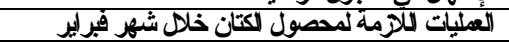 & 年 \\
\hline$\Lambda . . \Lambda \mu$ & Y... & I.rV & اللياض الززغي في محصول (لبصل &.$\pi \varepsilon$ \\
\hline $9 \leq .97$ & Y.19 & Y.IY & رعاية النعاج والغزلت &. To \\
\hline AM.Ir & $1 . \S 1$ & $1 . r 9$ & 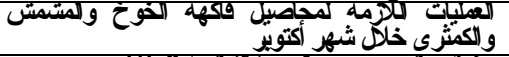 & דז. \\
\hline AN.TT & P... & T.29 & 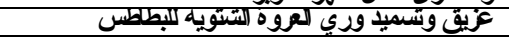 &.$T V$ \\
\hline $90.1 \mathrm{~V}$ & Y.YO & Y.11 & زراعة محصول الفُول البلادي &. $\mathrm{r} \Lambda$ \\
\hline 9Y. 57 & $r .19$ & r.. & 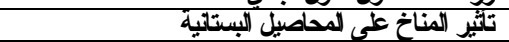 & .49 \\
\hline QV.rT & r..V & T... & الأمرل اضتي تصيب محصول البطلطس &.$\varepsilon \cdot$ \\
\hline AY.YV & T.MT & Y.IY & إنتاج شتتلات الطماطُ &.$\leqslant 1$ \\
\hline $1 \ldots .+$ & $Y .17$ & Y.17 & 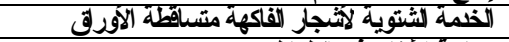 & .हT \\
\hline 9 9.\$1 & Y.YO & Y.Iई & صلاعة الأفلقي في الطملطم &.$\varepsilon \pi$ \\
\hline$\Lambda 7 . \leqslant V$ & T.IT & 1.00 & فسائل النظيلي &.$\varepsilon \varepsilon$ \\
\hline $9 \Lambda . \vee$. & Y.T & T.MT & زراعة محصول القمح &..$_{0}$ \\
\hline $1 \cdot .90$ & Y.. T & $1 . \leqslant Y$ & تقالوي محصول القمح & .27 \\
\hline 97.49 & 1.0 & 1.57 & زراعة محصول العس &.$\varepsilon V$ \\
\hline$\Lambda \varepsilon .7 Y$ & t.rT & Y.. & زيادة إتتاج الجاموس &.$\varepsilon \wedge$ \\
\hline $\mathrm{Vq. \varepsilon V}$ & T.MT & Y... & ألتُشتية في طو فَف النحل &.$\Sigma 9$ \\
\hline $94 . V 1$ & T.YT & Y.I & زراعة محصول الثُبري & .0. \\
\hline $9 . .19$ & $Y .1 \leqslant$ & Y.. I & العمليات الزيراعَة لأتجز الموالج في نوفمبر & .01 \\
\hline 94.09 & r... & r.00 & 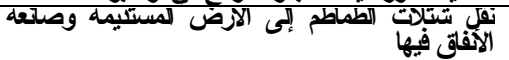 & .Or \\
\hline $9 Y .0 \mathrm{~V}$ & Y.YA & T.IV & زراعة محصول الكتان & .05 \\
\hline QY.r. & r..r & 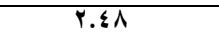 & تسمين العجول & $.0 \xi$ \\
\hline A.. $7 \mathrm{~V}$ & Y. $\{0$ & T.YY & تغنية الأمهات العثل & .00 \\
\hline $9 \leqslant .0 \leqslant$ & T.01 & T.\$O & تسمين بلراى (للحم & .07 \\
\hline $9 Y .9 Y$ & $1.0 \mathrm{r}$ & $1 . \leqslant 0$ & مشتلّ محصول البصل & $.0 \mathrm{~V}$ \\
\hline$\Lambda \cdot .1 \mu$ & $\begin{array}{r}. T 1 \\
\end{array}$ & Y.. & الحشرات القُشرية في نظيل البلح ب & .01 \\
\hline $1 \ldots$. & Y.IV & T.IV & جمع محصول البرقوقق & .09 \\
\hline QY.AT & Y.07 & Y.\&T & العملّيت اللاممة لمحصول المشمش خلال شهر يونيو & .7 \\
\hline १จ.จ १ & r.1. & $r . .7$ & 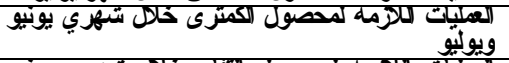 & .7) \\
\hline $9 \mathrm{V..17}$ & r.r & $r .11$ & ويوليّيتات الملامه لمحصول التفاح خلل شتهري يونيو & זד. \\
\hline $9 \vee .74$ & Y.OV & Y.OT & 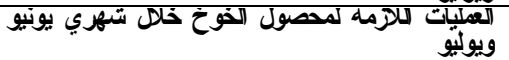 & זד. \\
\hline N9.VI & IEA.TO & 1Ts.1T & 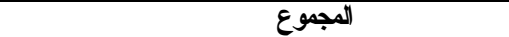 & \\
\hline
\end{tabular}

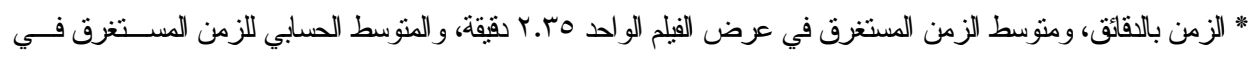

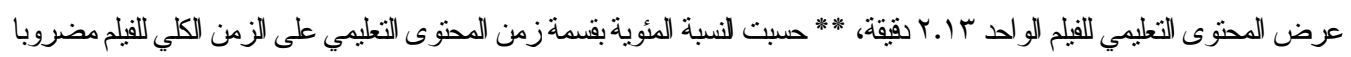

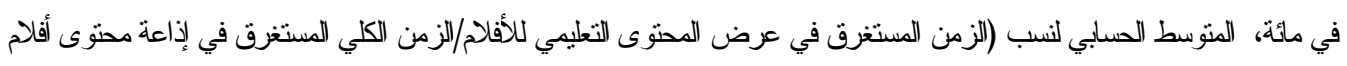

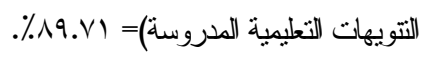




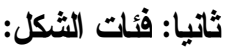

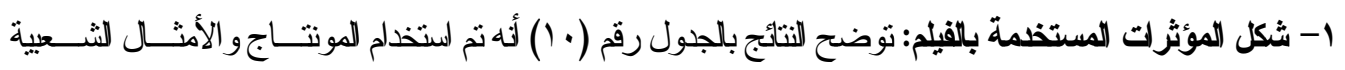

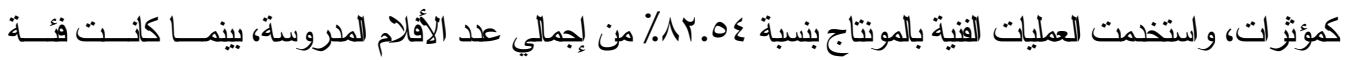

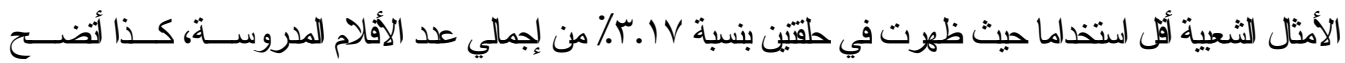

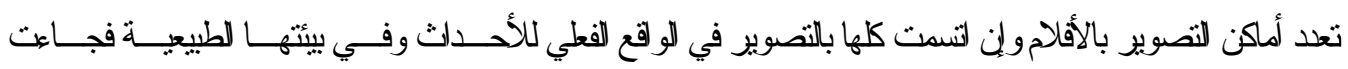

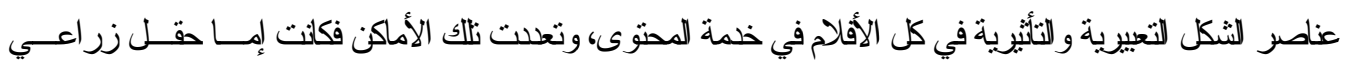

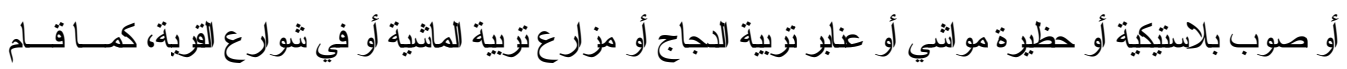
بإلقاء التوصيات للفنية معلقين محترفين بما يشكل عامل جنب. جلول رقم ( • 1): العدد والنسبة المئوية لأفلام التتويهات الإرشلدية الزراعية تبعا لثكل المؤثرات بالفيلم الواحد

\begin{tabular}{|c|c|c|}
\hline$\%$ & 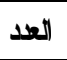 & شكل المؤثرث \\
\hline Ar.oई & or & - لستخدام المؤثزات الفنية بالمونتاج (المؤثزات البصرية) \\
\hline r.IV & $r$ & - أمثال شعبية \\
\hline
\end{tabular}

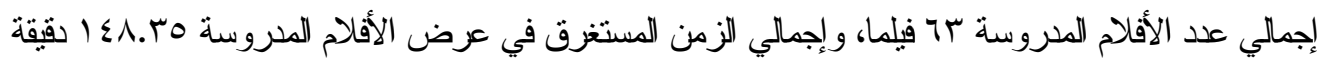

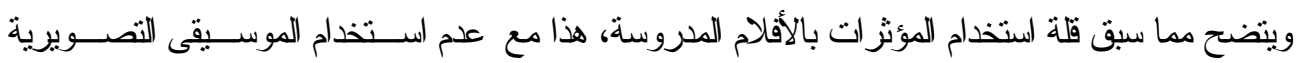
المصاحبة للمحتوى التعليمي أو الستخدام المناسب من (آيات القر آن الكريم، و الأحاديث للنبوية، والأقو ال المـأثنورة،

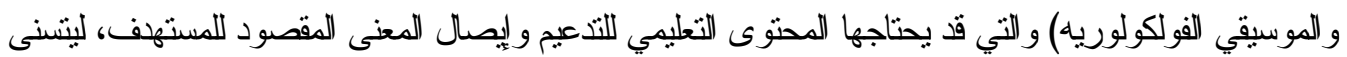
الإفناع بالتوصيات الفنية المر اد نتنيها.

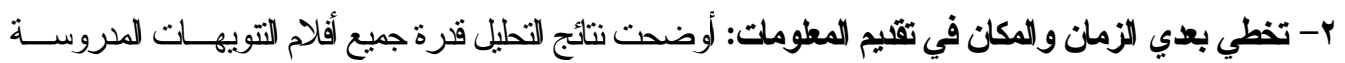

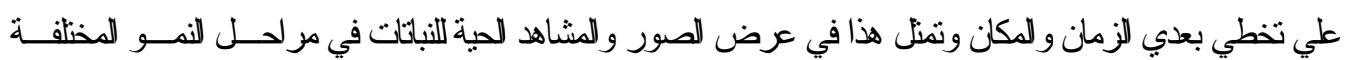

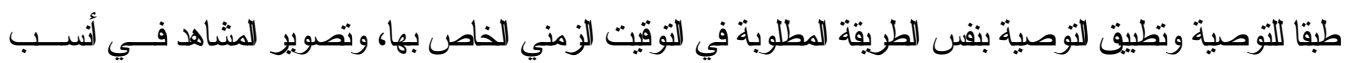
مو قع لييئة الريفية وفي الأماكن الو قعية بما يتثق والمحتوي التعليمي ويعكس و اققعا فعليا مقنعا.

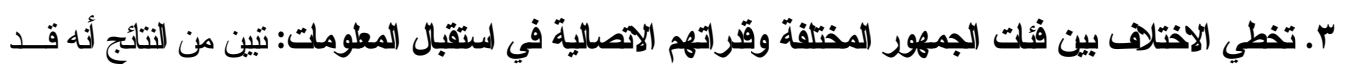

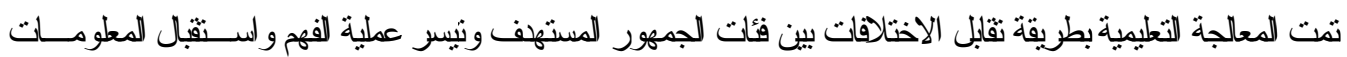

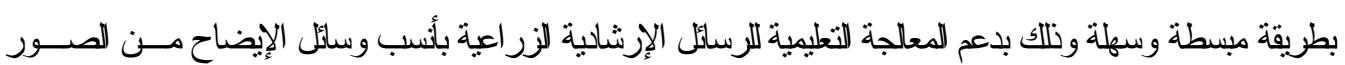
و الرسوم و للصوص التوضيحية، إضلقة إلى ما يقدم نص التطليق من دعم في تز لمن مع الصورة.

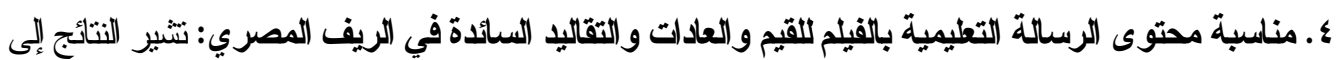

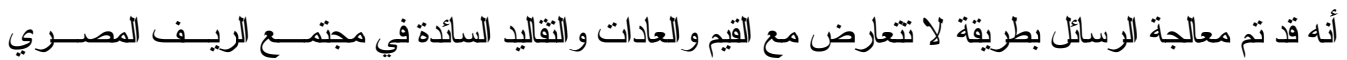

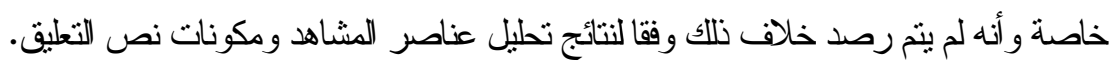

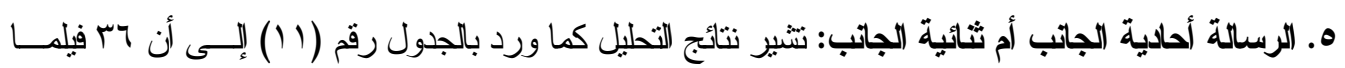

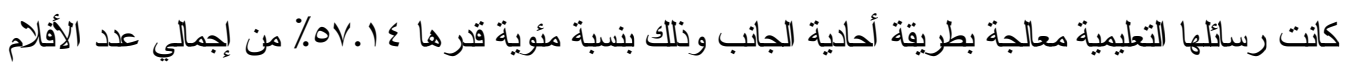

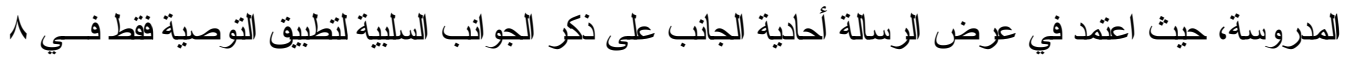

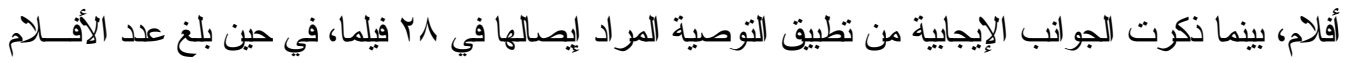

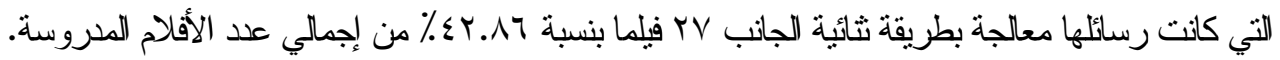


جدول رقم (1 1 ): العلد والنسبة المئوية لأفلام التتويهات الإرشادية الزراعية وفقا لمعالجة الرسلالة بطريقة

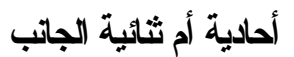

\begin{tabular}{|c|c|c|}
\hline \% إلى إجمالي عدد الأقلام المسروسة & عد الأقلام & الرسالة أحالية الجاتب أم ثثائية الجلب \\
\hline ov.ls & 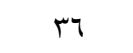 & - الرسالة أحادية الجاتب \\
\hline$\leqslant$ \&.AT & TV & - الرسالة ثثئية الجانب \\
\hline $1 \ldots \ldots$ & זד & المجموع \\
\hline
\end{tabular}

إجملي عدد الأفلام المدروسة با فيلما

ويعد أسلوب معالجة الرسالة التعليمية بطريقة ثنائية بعرض الجوانب الإيجابية والسلبية من أسلاليب التـأثنير

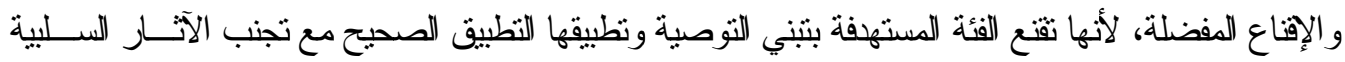
وتحقيق المنفعة.

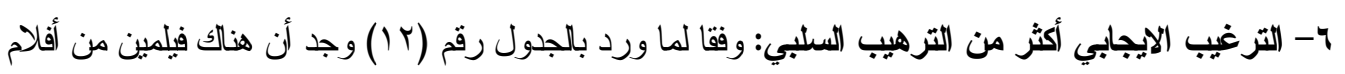

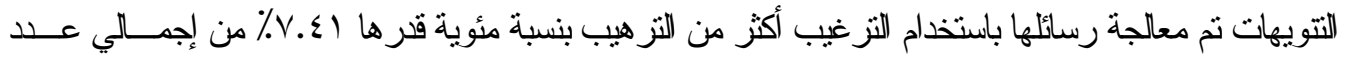

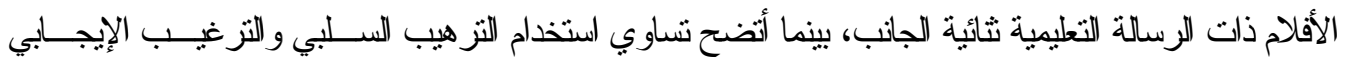

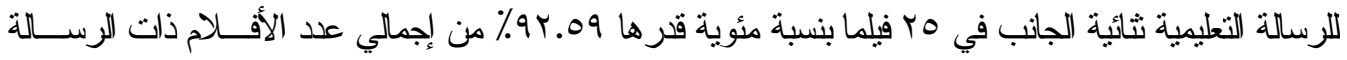
التعليمية ثثائية الجانب. جدول رقم (r ا): العلد والنسبة المئوية لأفلام التتويهات الإرشادية الزراعية وفقا لمقارنة استخدام الترغيب

\begin{tabular}{|c|c|c|}
\hline \multicolumn{3}{|c|}{ الإيجلبي بلترهيب السلبي } \\
\hline \% إلى إجملي عد الأفلام المروسة & علد الأفلالم & مقارنة استخدام التزغيب الإجبي بالترهيب لسلبي \\
\hline V.\&) & r & - لستخدام النز غيب الإيجابي أكثر من السلبي \\
\hline 99.09 & ro & - نساوي استخدام التزرهيب السلبي و التزرغيب الإيجبي \\
\hline $1 \ldots$. & rV & المجموع \\
\hline
\end{tabular}

إجمالي عدد الأفلام المدروسة سج فيلما، والأفلام المعالجة بطريقة ثثائية الجانب TV فيلما استخدام الأسلوبين معا وباتزان قد يحقق للهف بشكل موضوعي ومنطقي و بما يدعو إلى نبني التوصية.

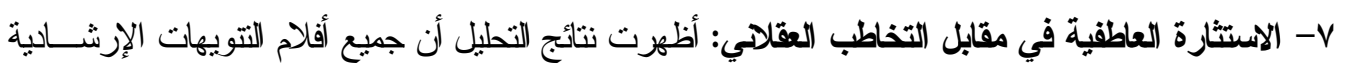

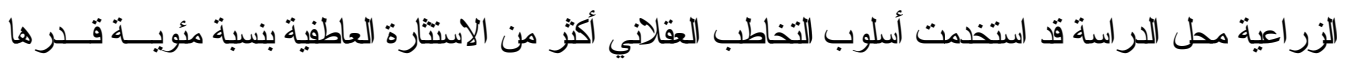

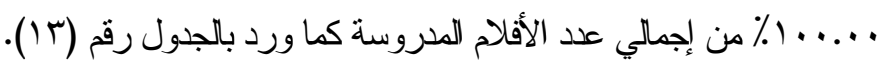

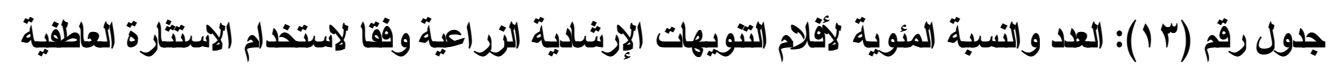

\begin{tabular}{|c|c|c|}
\hline \% إلى إجملي عد الأقلام المدروسة & عد الأفلاتم & فئلت استخدام الاستثارة العلطقية في مقابل التخاطب العقلايي \\
\hline $1 \ldots$. & זד & - استخدام التخاطب العقلاني أكثر من الاسنثارة العاطفية \\
\hline$\cdots$ & - & - لستخدام الاسنتارة العاطفية أكثر من التخاطب العقلاني \\
\hline $1 \ldots$. & r & 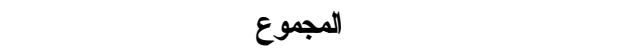 \\
\hline
\end{tabular}

إجمالي عدد الأفلام المدروسة ب7 فيلما 
وقد تزجع أهمية استخدام الأسلوب العقلاني في تقليم الحجج و البر اهين القوية و المنطقية بــــــــــي إلـى

^- شكل العياق: أوضحت نتائج التحليل وجود فئة و احدة من فئات شكل السياق كانت نبالل التعليق بين أثثين من المعلقين (رجل و امرأة) في جميع الأفلام محل الدراسة.

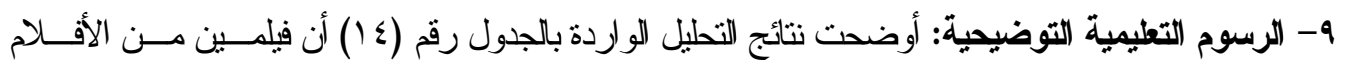

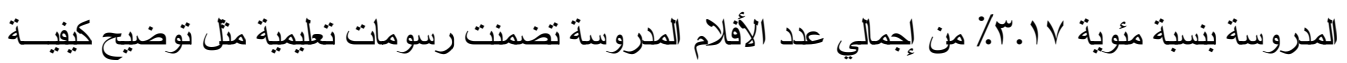

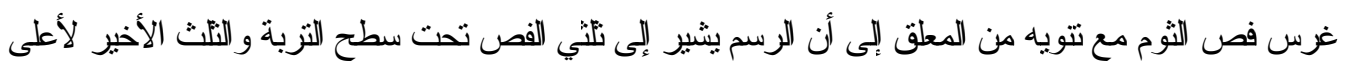

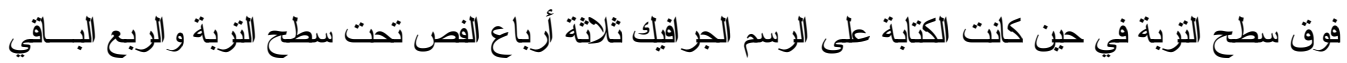

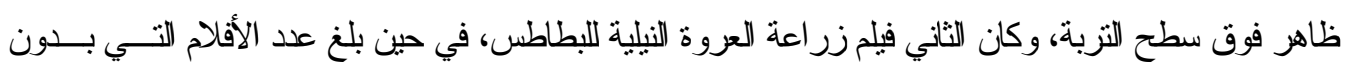

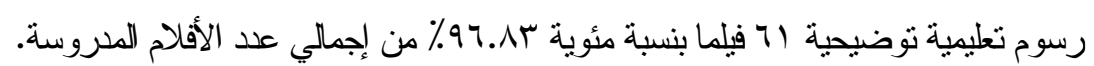

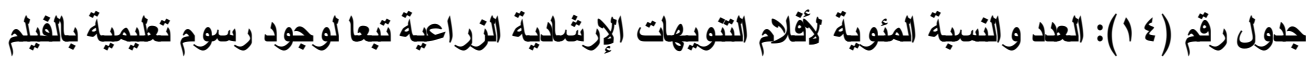

\begin{tabular}{|c|c|c|}
\hline \% إلى إجمالي عدد الأفلام الدروسة & علد الأكلام & الرسوم \\
\hline r.IV & $r$ & - \\
\hline $97 . \wedge \%$ & 71 & - بلون رسومات \\
\hline $1 \ldots \ldots$ & 45 & المجموع \\
\hline
\end{tabular}
إجمالي الأفلام المدروسة با فيلما

• 1- الصور التعليمية التوضيحية: تشبير نتائج التحليل إلى ظهور الصور التعليمية التوضيحية في ^؟ فيلم بنسبة

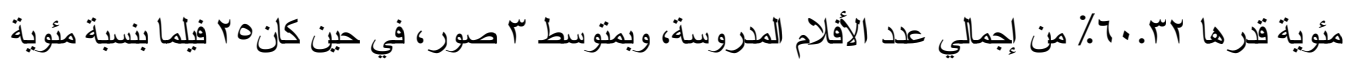
14 9 \% من إجمالي عدد الأقلام المدروسة بدون صور تعليمية توضيحية وفقا للجدول رقم (10).

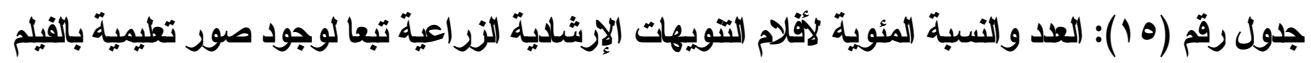

\begin{tabular}{|c|c|c|}
\hline \% إلى إجمالي عد الأفلام العروسة & عد الأقلات & الصور \\
\hline $7 . . r T$ & rл & - \\
\hline$r 9.71$ & ro & - - بلون صور \\
\hline $1 \ldots$. & 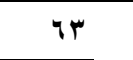 & المجموع \\
\hline
\end{tabular}
إجمالي عدد الأفلام المدروسة سج فيلما

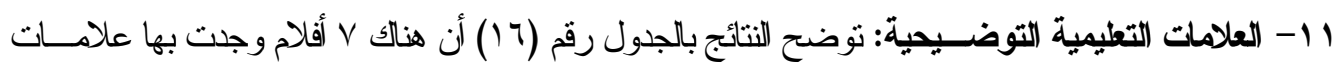

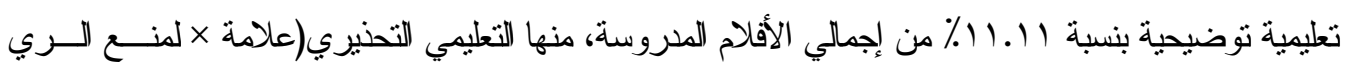

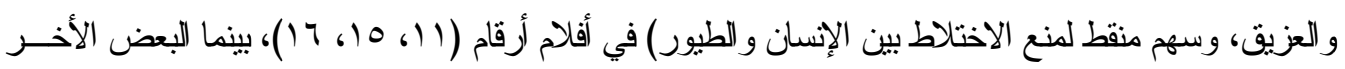

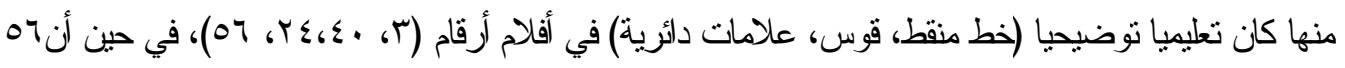

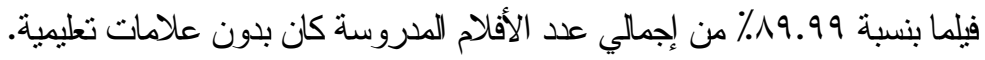


جدول رقم (1 1): العلد و النسبة المئوية لأقلام التنويهات الإرشلاية الزراعية تبعا لوجود علامات تعليمية بالفيلم

\begin{tabular}{|c|c|c|}
\hline \% إلى إجمالي عد الأقلات المروسة & عد الأفلام & 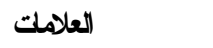 \\
\hline 11.11 & $v$ & 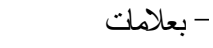 \\
\hline 19.99 & 07 & - بلون علامات \\
\hline $1 \ldots$. & r & المجموع \\
\hline
\end{tabular}

إجمالي عدد الأفلام المدروسة سج فيلما

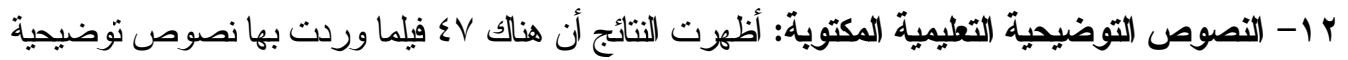

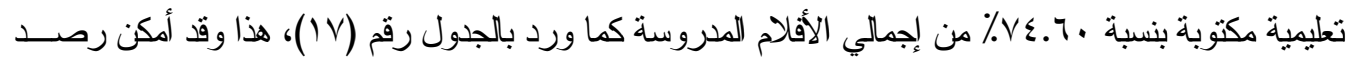

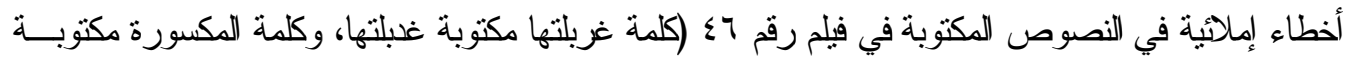

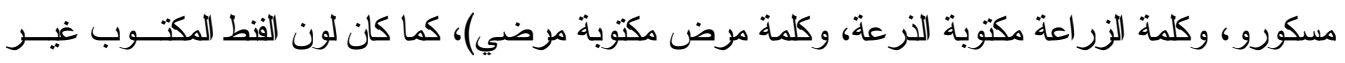

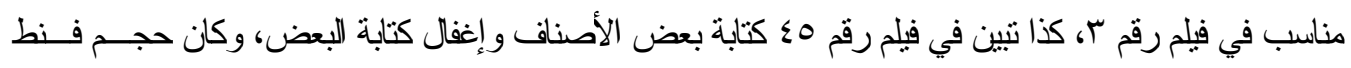

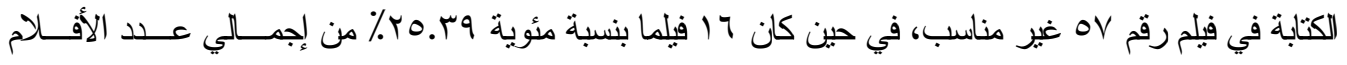
الدروسة بدون نصوص نوضيحية تعليمية مكتوبة.

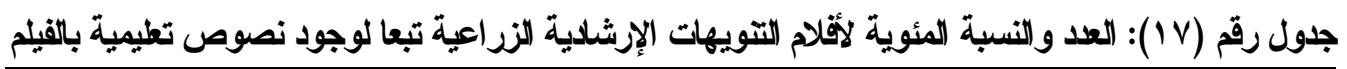

\begin{tabular}{|c|c|c|}
\hline \% إلى إجمالي عد الأكلام المروسة & عد الأفلاتم & النصوص \\
\hline$V \varepsilon .7$. & $\leqslant V$ & - بنصوص \\
\hline ro.rq & 17 & - بلون نصوص \\
\hline $1 \ldots$ & r & المجموع \\
\hline
\end{tabular}

إجمالي عد الأفلام المدروسة سج فيلما

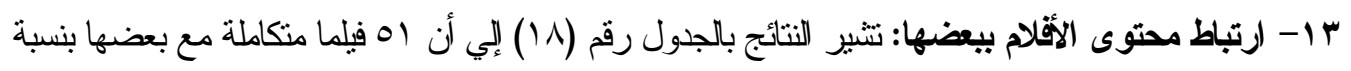

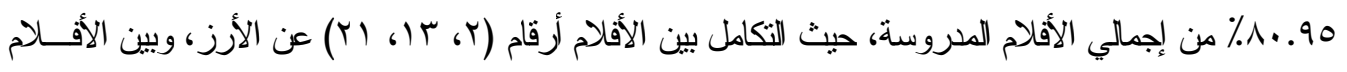

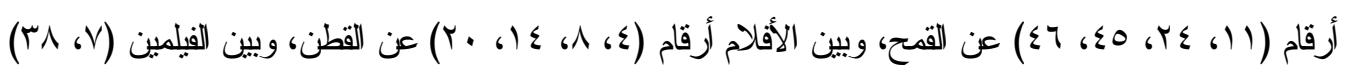

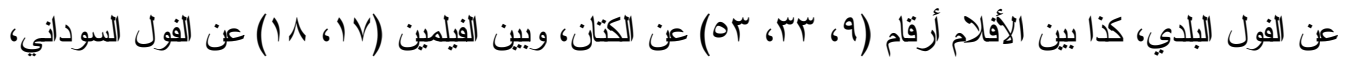

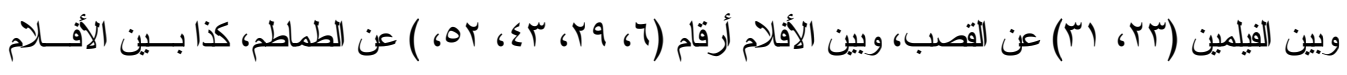

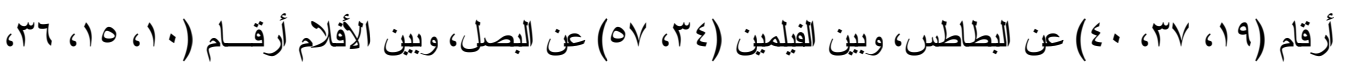

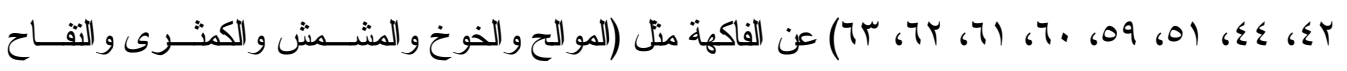

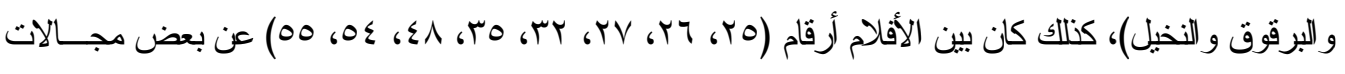

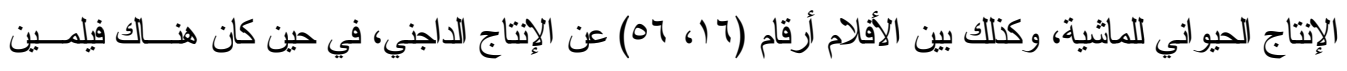

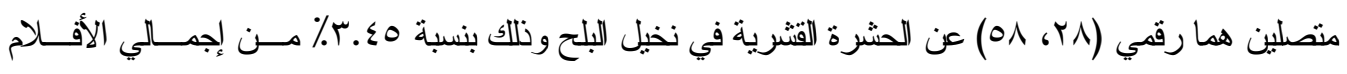

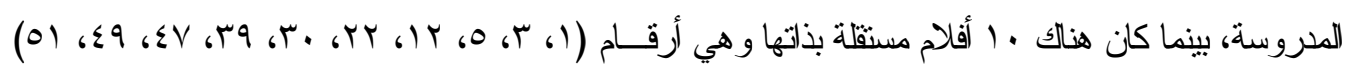

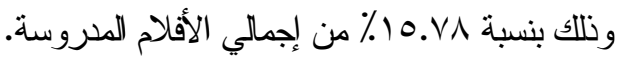


جلول رقم (1) (1): العدد والنسبة المئوية لأفلام التويهات الإرشادية الززاعية تبعا لارتباط محتوى الأفلام

\begin{tabular}{|c|c|c|}
\hline \% إلى إجمالي عد الأفلام الملروسة & عد الأقلام & ارتباط محتوى الأفلام المدروسة بيعضها \\
\hline r.IV & r & أفلام متصلة \\
\hline $1 . .90$ & 01 & أفلام منكاملة \\
\hline $10 . \vee \wedge$ & 1. & أفلام مستقلة بذتها \\
\hline $1 \ldots$. & 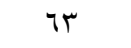 & 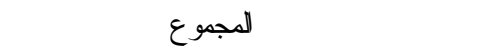 \\
\hline
\end{tabular}

إجمالي عدد الأفلام المدروسة بح فيلما

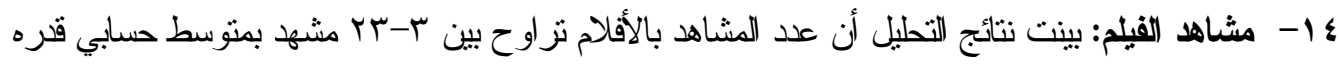

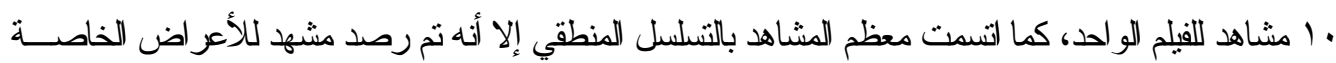

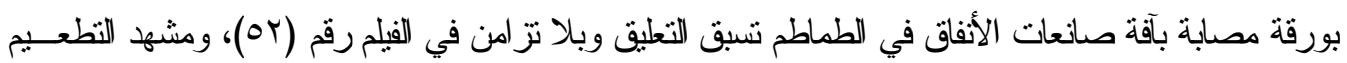
للطيور قبل الممارسات الوقائية في الفيلم رقم (10).

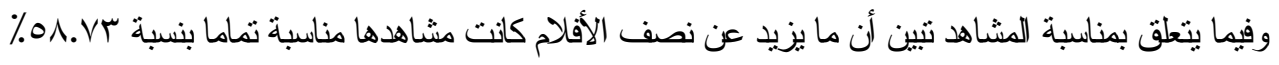

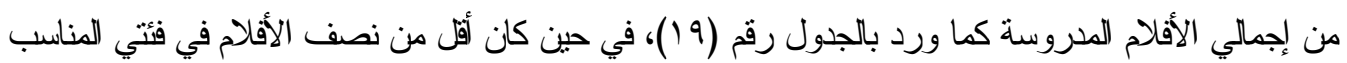

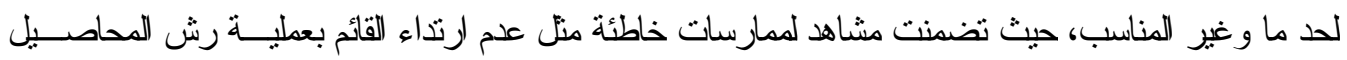

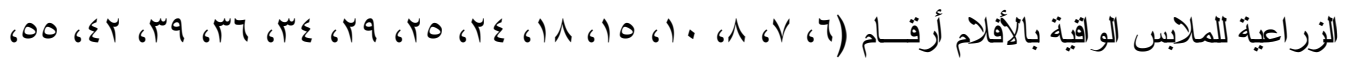

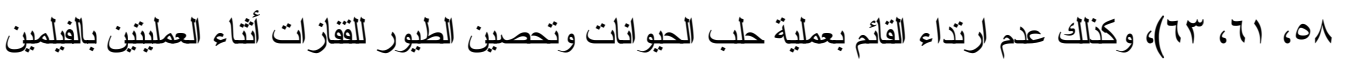

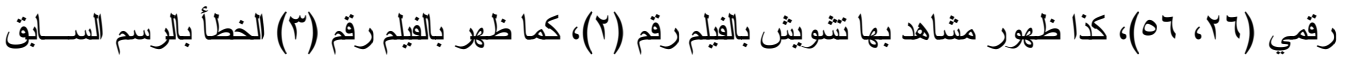

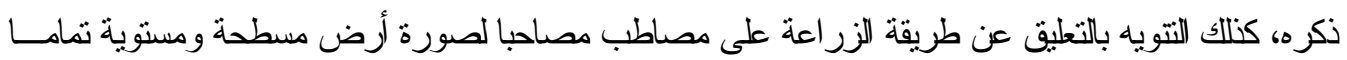

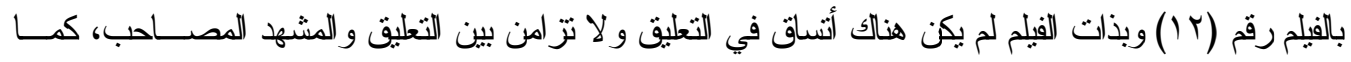

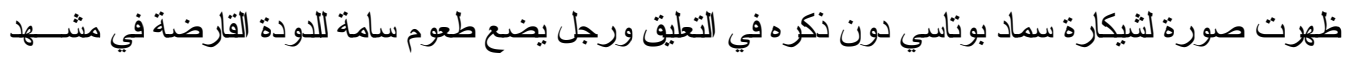

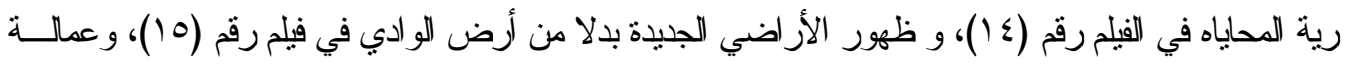

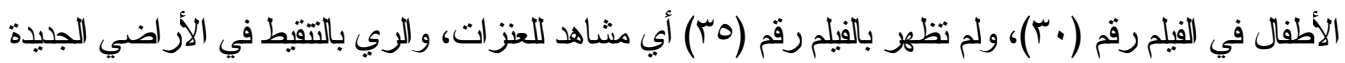

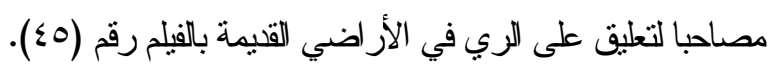

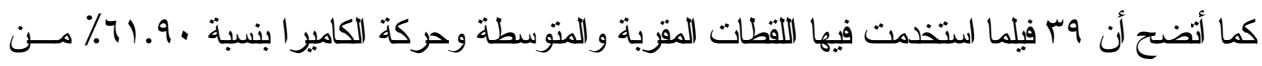
إجمالي الأفلام الدروسة، بينما كانت نسبة الأفلام التي ستخلم فيها اللقطات المقربة والمتوسطة والطويلة وحركة

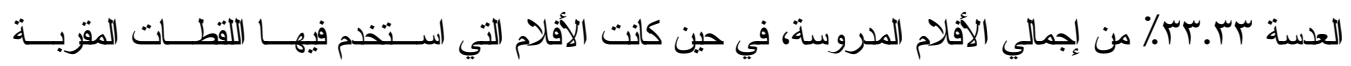

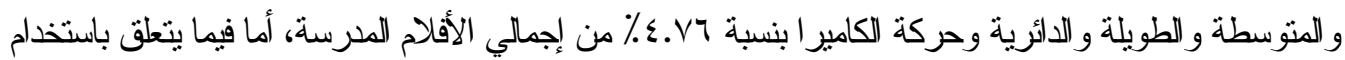

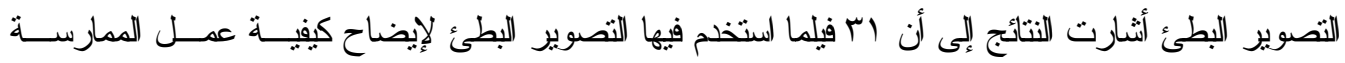

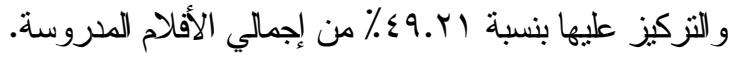


جلول رقم (9 1): العلد والنسبة المئوية لأفلام التتويهات الإرشادية الزراعية تبعا لنوعية اللقطات المأخوذة واستخدام التصوير البطئ في المشاهد

\begin{tabular}{|c|c|c|}
\hline \% إلى إجمالي عد الأقلام المدروسة & عد الأفلام & 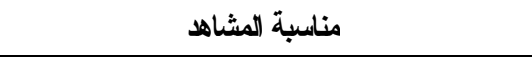 \\
\hline$O \wedge . V T$ & rv & - مناسبة \\
\hline $1 V . \leq 7$ & 11 & - لحدما \\
\hline rT.AI & 10 & - غير مناسبة \\
\hline $1 \ldots$ & זי & المجموع \\
\hline \% إلى إجمالي عد الأقلام المدروسة & عد الأفلام & اللقطات بالأقلام \\
\hline 71.9. & rq & - لقطات مقربة ومتوسطة وحركة كاميرا \\
\hline 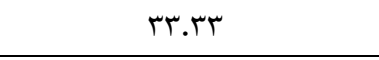 & r) & - لقطات مقربة منوسطة وطويلة وحركة عسه \\
\hline$\varepsilon . V 7$ & r & كاميرا - قططات مقربة منوسطة وطويلة ودئرية وحركــة \\
\hline $1 \ldots \ldots$ & 74 & 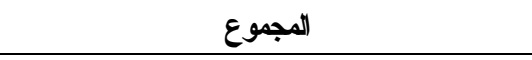 \\
\hline \% إلى إجمالي عد الأقلام المدروسة & علد الأقلام & استخدام التصوير البطئ \\
\hline$\{9 . Y)$ & 省 & 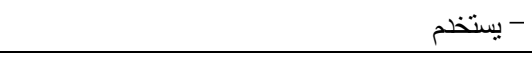 \\
\hline $0 . .19$ & rt & 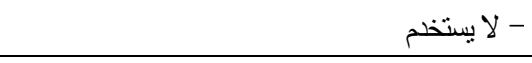 \\
\hline $1 \cdots \cdots$ & 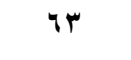 & 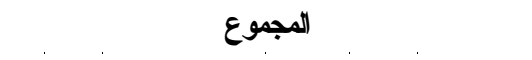 \\
\hline
\end{tabular}

إجمالي عدد الأفلام المدروسة با فيلما، متوسط عدد المشاهد ـ ـ مشاهد.

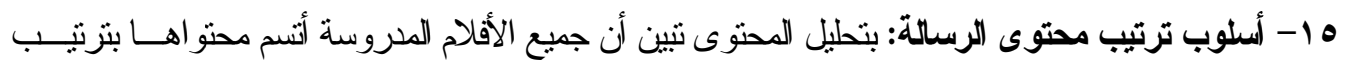

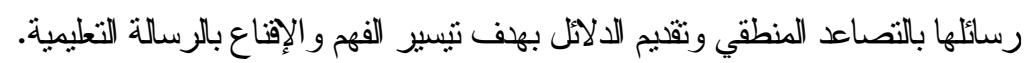
17

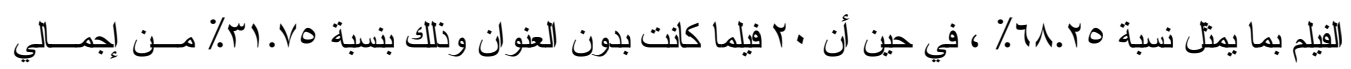

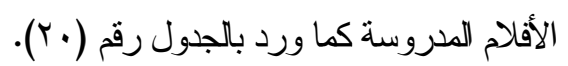

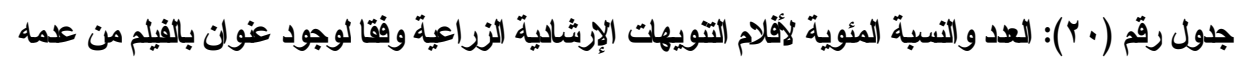

\begin{tabular}{|c|c|c|}
\hline \% إلى إجمالي عد الأقلام الملروسة & عد الأقلات & وجود غنوان \\
\hline TA. YO & r & - يوجد \\
\hline m.vo & $r$ r. & - ل لم يوجد \\
\hline $1 \ldots$ & 4 & المجموع \\
\hline
\end{tabular}
إجمالي الأفلام المدروسة سج فيلما

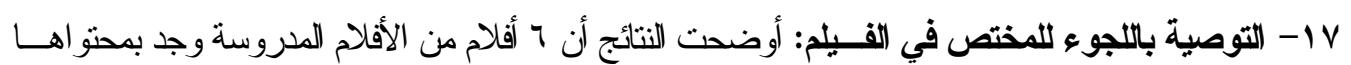

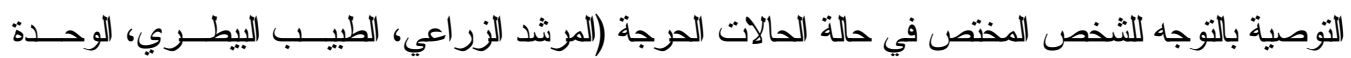

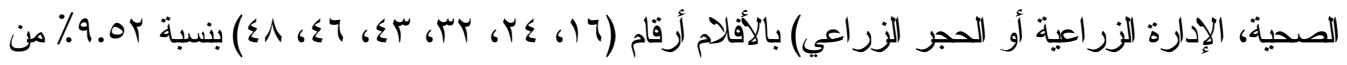

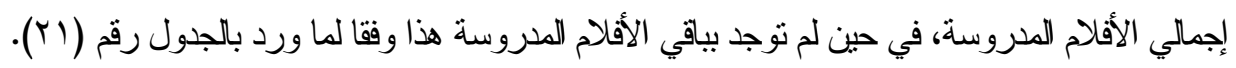


جدول رقم ( اYץ): العدد والنسبة المئوية لأفلام التتويهات الإرشادية الزراعية وفقا لوجود التوصية بالتوجه للمختص بالقيلم من عدمه

\begin{tabular}{|c|c|c|}
\hline \% إلى إجمالي علد الأفلام المسروسة & علد الأفلام & التوصية بلتوجه للمختص \\
\hline 9.04 & 7 & 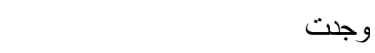 \\
\hline $9 . . \Sigma \wedge$ & ov & 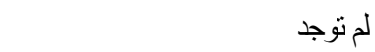 \\
\hline $1 \ldots \ldots$ & זי & المجموع \\
\hline
\end{tabular}

إجمالي عدد الأفلام المدروسة با فيلما

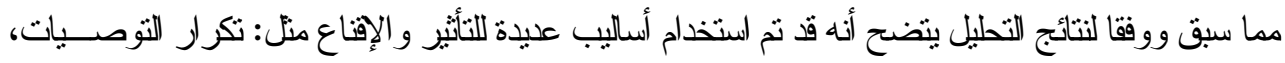
وتحليد مصدر المادة للعية، و ارتقاع مسنتى لمحتوى التعليمي للأفلام وجدة التوصيات بالأفلام، واستخدام أثنكال

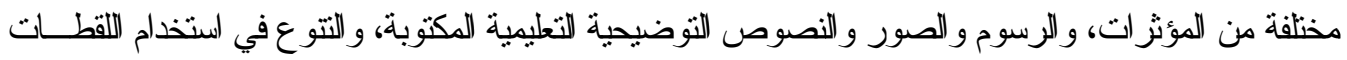

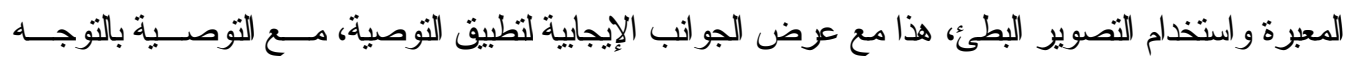

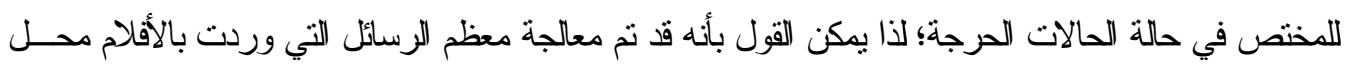

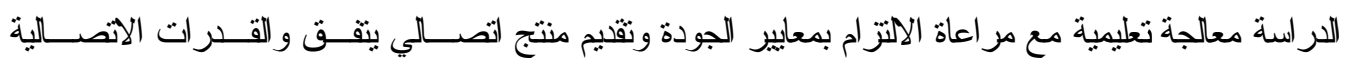
للمستهافين من حيث الثنكل و المضمون.

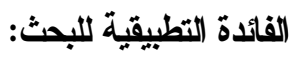

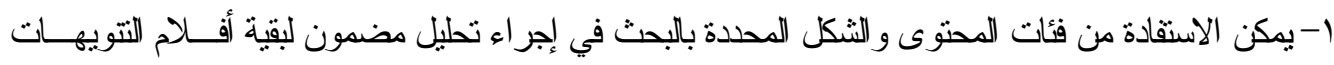

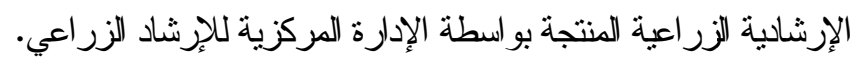

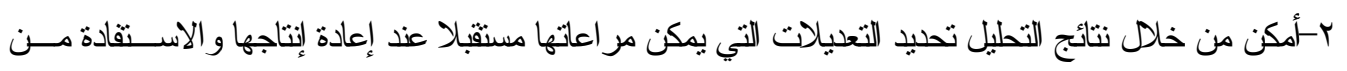
النتائج عند إعداد أفلام جيدة. المراجع

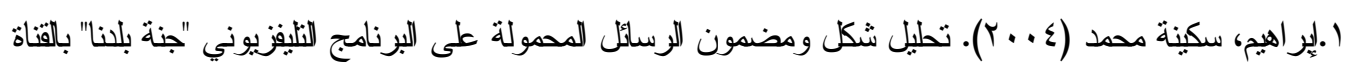

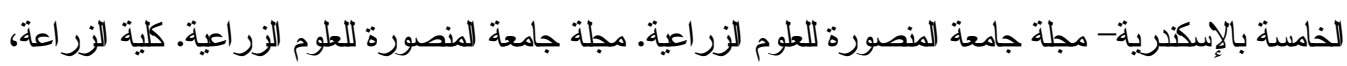

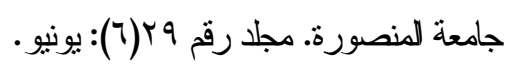

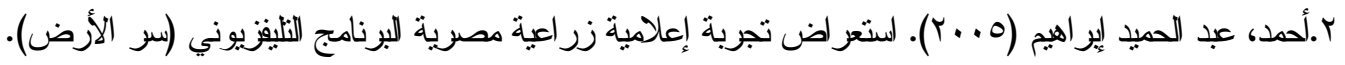

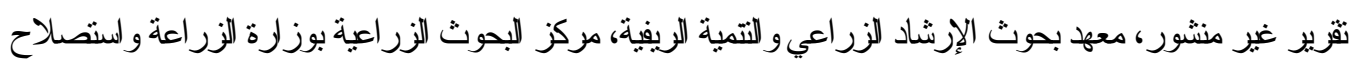
الأراضي مركز لبحوث الزراعية.

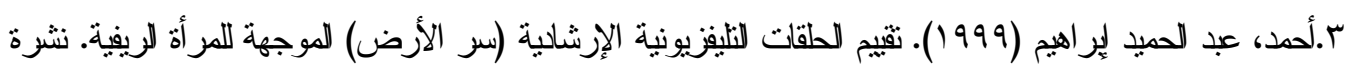

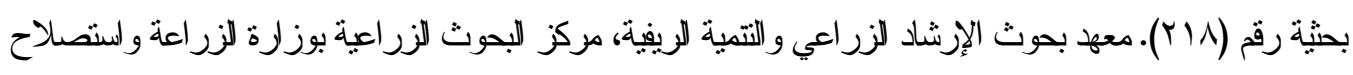
الأر اضب.

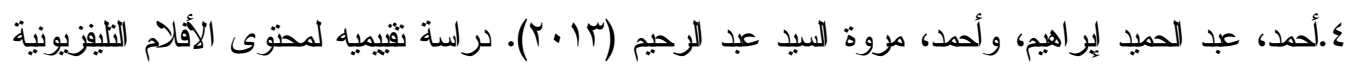

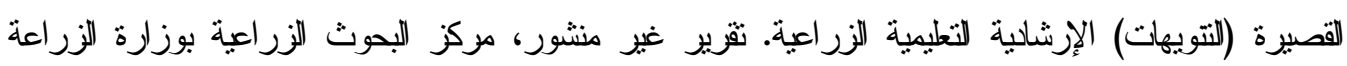
ولستصلاح الأرلبي. أكتوبر . 
ه.أحمد، عبد الحمبد إير اهيج؛ والجارحي، أمان علي؛ ومصطفى، حسن لحمد (1999). صورة لمرأة الهصرية في

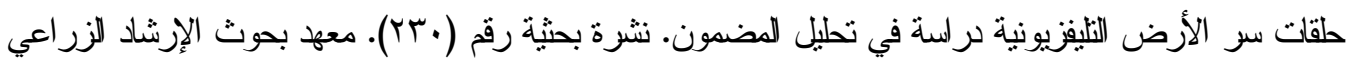

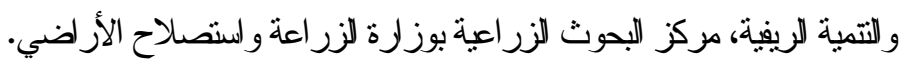

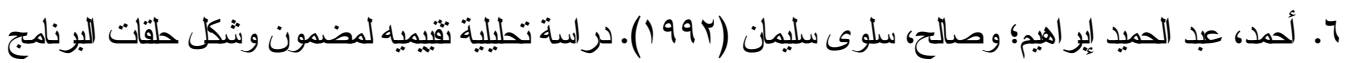
التليفزيوني الإرشادي "سر الأرض"، نشرة بحثية رقم (AV). معهد بحوث الإرشاد الزراعي والنتيية الريفية، مركز

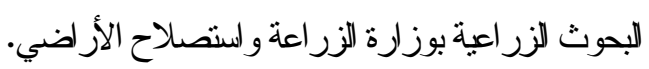

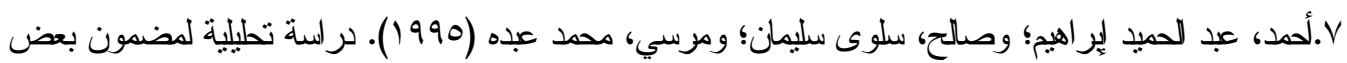

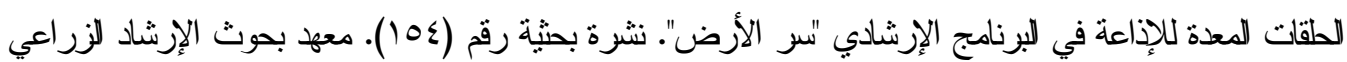

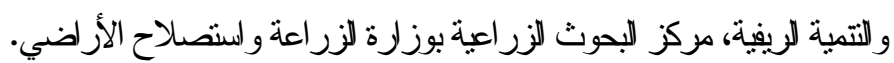

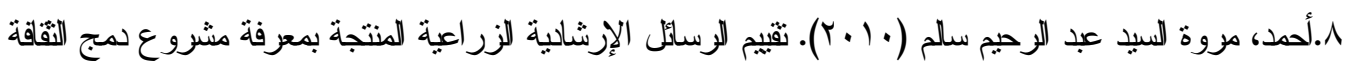
السكانية و للييئة في الإرشاد الزر اعي بمحافظة لبحيرة. رسلة لكتور اه غير منشورة. كلية للزر اعة، جامعة القاهرة.

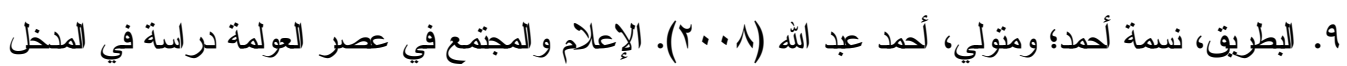

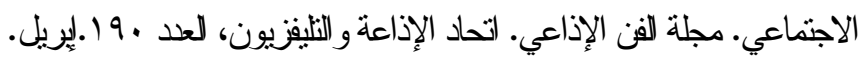

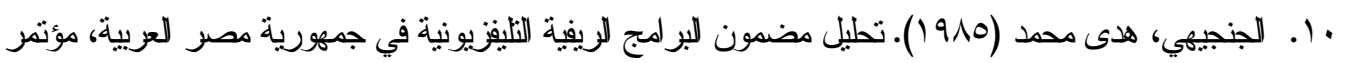

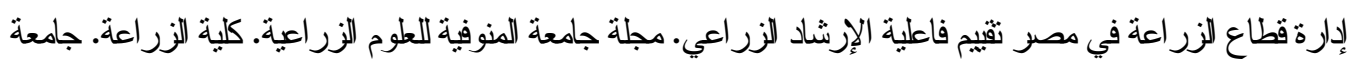

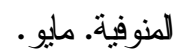

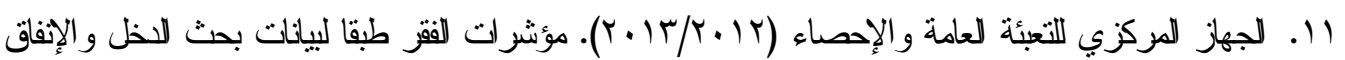
و الاستهالاك. الجهاز العركز للتعبئة العامة والإحصاء.

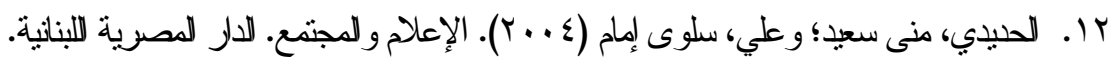

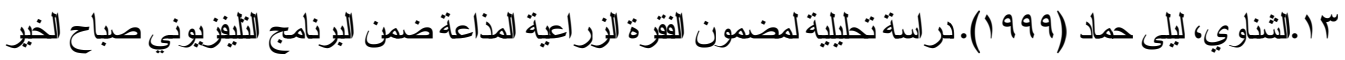

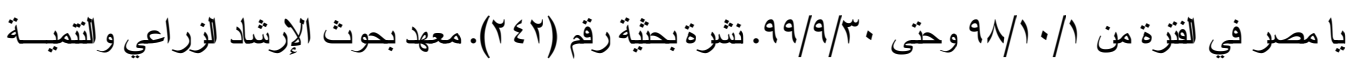

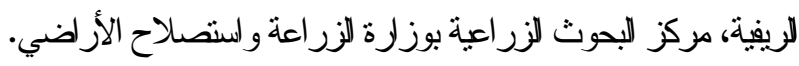

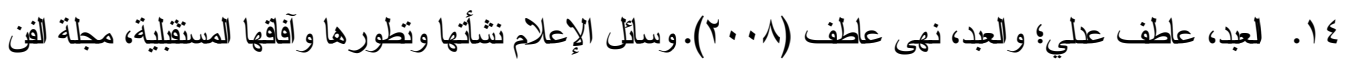
الإذاعي. تحاد الإذاعة والتليفزيون، العد 119 ا ـ ينلير.

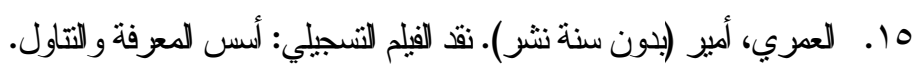

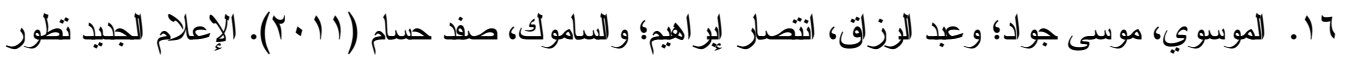

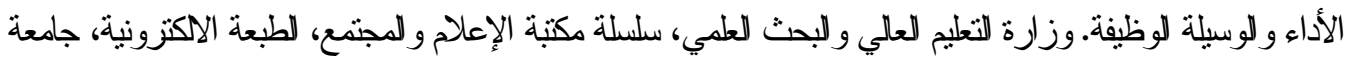

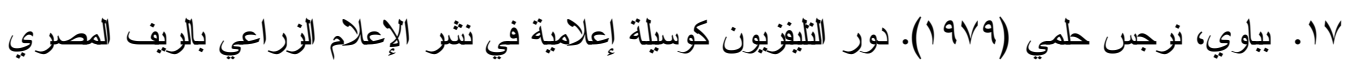

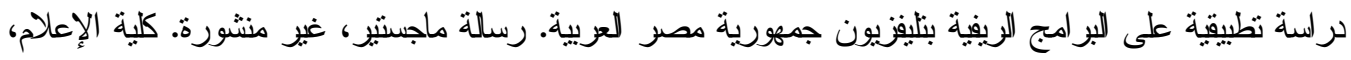




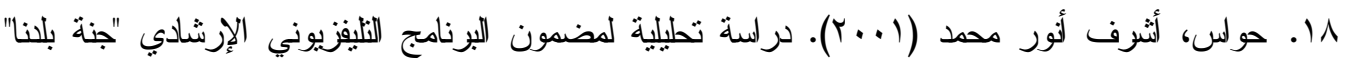

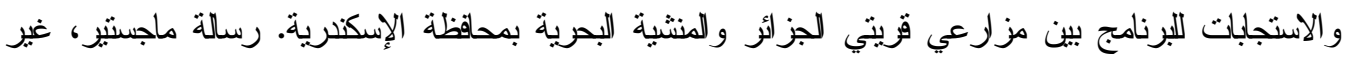
منشورة. كلية الزر اعة، جامعة الإنكندرية.

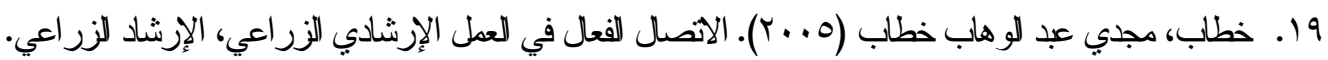

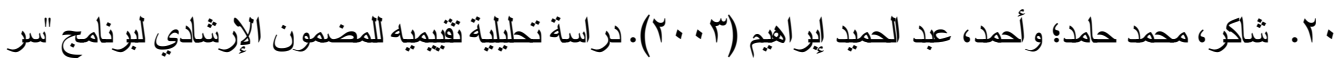

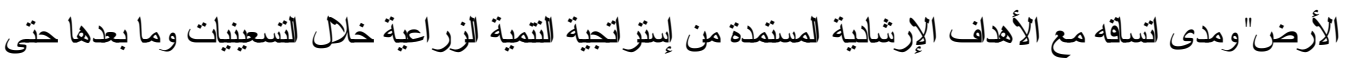

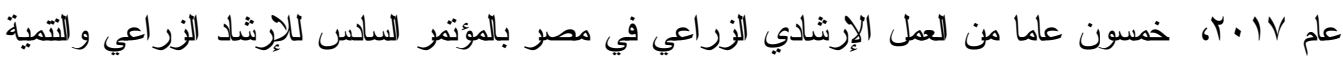

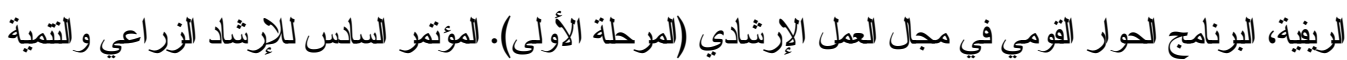

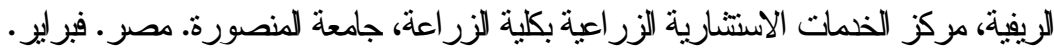

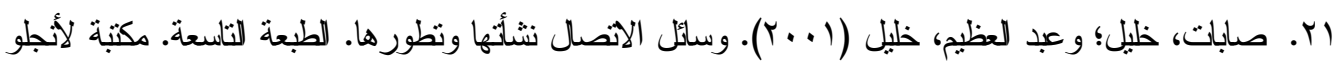
المصرية. القاهرة.

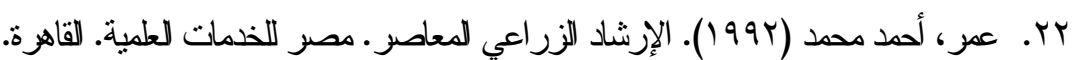

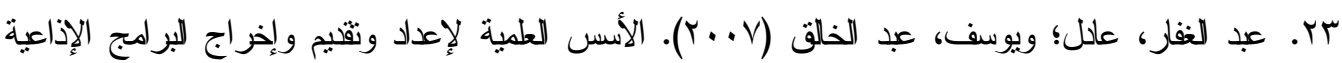

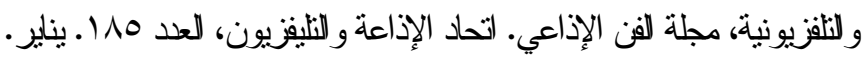

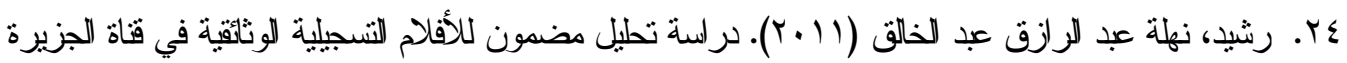

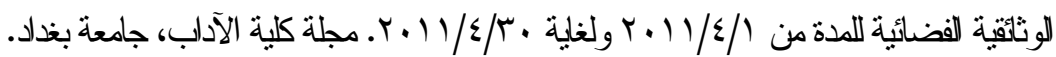

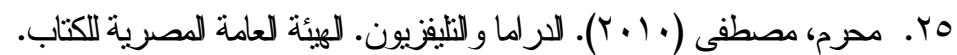

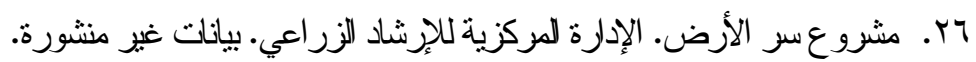

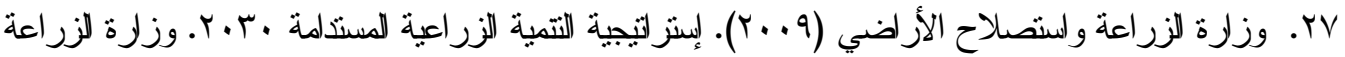
واسنصلاح الأرلي.

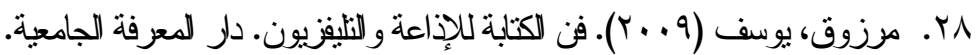

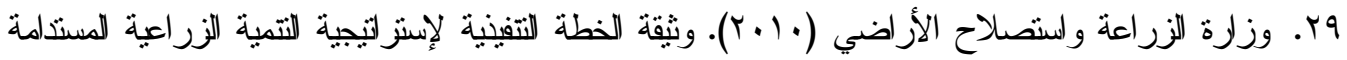

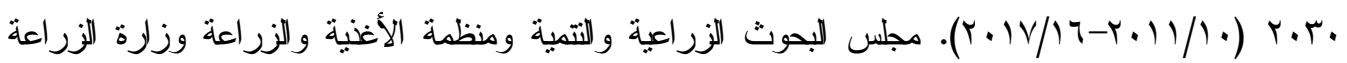

$$
\text { واستصلاح الأرلني. }
$$

30. Balit, Silvia (1999). Voices for change- rural women and communication, communication approaches. Food and agriculture organization of the United Nations. Rome .available at: http://www.fao.org/docrep/×2550e/x2550e04.htm

31. Jungeling, Ingy (1993). Guidelines on fisheries extension (in the Bay of Bengal region). Bengal programme, and FAO. Madras, India.

32. MOALR; UNFPA; and FAO (2005). Mainstreaming population, environment and food security issues into agricultural extension programmes, Project Document. FAO Office. Cairo.

33. Schlote. Elke (2010). Education TV worldwide. International TV professionals' experiences and opinions. Internationales Zentralinstitut für das Jugend- und Bildungsfernsehen (IZ) beim Bayerischen Rundfunk. 


\title{
CONTENT ANALYSIS FOR AGRICULTURAL EXTENSION TELEVISION SHORT FILMS (INTIMATIONS)
}

\author{
MARWA EL-SAYED AABDEL EL-RHIME SALEM AHMED \\ and ABDEL-HAMID IBRAHIM AHMED
}

Agricultural Extension and Rural Development Research Institute- ARC- Giza- Egypt

(Manuscript received 13 May 2015)

\begin{abstract}
$\mathrm{T}$ his research aimed at identifying the extent of compliance in production rules and specifications for form and content for the TV short films (TV spots-video clip) called intimations that produced by The Central Administration of Agricultural Extension Services CAAES, to increase the effectiveness of these intimations and achieve their educational goals with the verification of educational content match with the agricultural extension services goals in Egypt according to 2030 agricultural development Strategy. The research was focus on 63 films, which represents about $44.06 \%$ of the total number of films produced, which were 143 films, where it was analyzed in terms of content and form. The main results were as follows:
\end{abstract}

\section{First, the results of content analysis:}

1- The results of content analysis showed that, the main fields derived from the 2030 agricultural development strategy gained the attention of producers, especially the second \& third main goals and its sub-goals except the development of the fisheries, and achieve some sub-goals in the main goals first; fourth; fifth; \& sixth, develop the production of intimations films in the next stages in accordance with the achievement of the goals derived from the strategy. Also there are four main fields of extension; these were in descending order as follow: the field of plant production; animal production; the preservation of environmental resources and maintenance; and public affairs, these in terms of the number of films and the time it takes to broadcast in minutes.

2- Plus the results showed that all studied films as a percentage of $100.00 \%$ the part of the educational content to the total time of the film in the category of $50.00 \%$ or more of the total time, well it turns out that all the films content under study been directly related to the main objective of each one, and that the content of the expressive elements and the elements of the scenes components, and the script all where carried ideas and lead to right interpretation meanings.

3- Also, results showed that, 42 films included over agricultural extension recommendations repeated more than once with deferent treatment, so it was not tedious, as well as were 16 films by percentage $25.39 \%$ from studies films the technical agricultural extension recommendations were not indicative, plus all studies films were not found silence periods to allow target groups to interact with the scene or a particular information. 
4- The results showed, that the source of scientific technical subject matter content of all the studied films were the ARC in collaboration with the CAAES of the Ministry of Agriculture and land reclamation, also average number of recommendations was seven recommendations per film, also the content of films under study deal with the needs of the target groups in all fields that have been counted, also it became clear the lack of a summary at the end of each studied films.

Second: the results of form analysis:

1- The results showed that it was the use of two types of technical effects were montage \& popular sayings, with multiple shooting locations characterized the whole filming in the actual reality of the events in their natural places, so came elements form expressive $\&$ influential in all the films in the content service, as showing the ability of all studied films skipped the time \& place span and represent this in view photos and actual scenes of plants in various stages of growth, according to the recommendation and implementation of the recommendation in the same circumstances required in its own time span.

2- As well as the results of content analysis showed that it has been treated to fit the differences between the target audiences and facilitated the understanding \& receiving of information process, in simple and easy manner with the promote of educational treatment of the agricultural extension messages in the most appropriate means of illustration of images, graphics/charts, symbols and text illustrations of this, in addition to the commentary narration depending on supporting text in sync with the picture.

3- As well as, there were 46 films integrated with each other by $79.31 \%$ of the total studied films, as most of the scenes of the studied films logical sequence was characterized, also that more than half of the studied films were the scenes perfectly suited up to $58.62 \%$ of the total studied films, with the presence of 39 films were used medium and telephoto shots and camera movement by $61.90 \%$ of the total studied film, photography the use of slow motion and focus in 31 films to illustrate how to do the practice by $49.21 \%$ of the total studied films.

4-Finally, the results showed that appropriate methods of influence and persuasion were used such as: repeated recommendations; identified the source of the scientific subject matter; the applicable of the educational content for films and appropriate recommendations, and the use of various forms of effects, graphics, images, text illustrations, and diversity in the use of the shots and the use of slow motion, with this offer positive aspects of the application of the recommendation, with a recommendation to go to the subject matter specialist in the case of critical situations. 